\title{
Beitrag zur Lehre von den Chorioidealsarkomen.
} Von

\author{
Dr. E. Pawel,
}

Assistenzarzt am St. Elisabeth-Krankenhaus in Halle a/s.

(Aus der Universitäts-Augenklinik in Halle a/S.)

Nachdem in der ersten Hälfte unseres Jahrhunderts auf dem Gebiete der intraocularen Tumoren noch die grösste Verwirrung geherrscht hatte, begann mit der Erfindung des Augenspiegels und mit der Anwendung der Virchow'schen Geschwulstlehre auf die Fremdbildungen des Auges eine neue Epoche. Erst jetzt war man in der Lage, diese Tumoren in ihren Anfängen und ihrem weiteren Verlaufe zu beobachten, und, was noch wichtiger, sich auf Grund der Kenntniss ihres anatomischen Baues uiber ihre Eintheilung und ihre Prognose zu verständigen. Schon die im Jahre 1868 fast gleichzeitig erschienenen grundlegenden Arbeiten von v. Graefe ${ }^{1}$ ) und $\operatorname{Knapp}^{2}$ ) hoben die Thatsache hervor, dass, im Gegensatz zu den friher geltenden Anschauungen fast ausschliesslich zwei Arten von malignen Tumoren im Auge vorkommen: Gliome, welche von der Netzhaut, und Sarkome, welche vom Uvealtractus ihren Ausgang nehmen; von dem klinischen Bilde der letzteren, die uns hier näher beschäftigen sollen, geben beide Autoren bereits eine eingehende, überaus naturgetreue Darstellung, und seither haben zahireiche weitere Veröffentlichungen die mitgetheilten Beobachtungen bestätigt. Mit der im Jahre 1882 publicirten Monographie von Fuchs ${ }^{3}$ ), die auf einer

1) v. Grae fe's Arch. f. Ophthalm. XIV.Bd. 2. Abth. S.101 ff. 1868.

2) H. Knapp, Die intraocularen Geschwülste. Karlsruhe 1868.

3) E. Fuchs, Das Sarkom des Uvealtractus. Wien 1882. 
Sammlung von 259 genauer beschriebenen Fällen basirte, lässt sich die Lehre ron dem klinischen Verlauf des Uvealsarkoms im Allgemeinen als abgeschlossen bezeichnen, und der Schwerpunkt neuerer casuistischer Mittheilungen ist daher nicht mehr in der Schilderung der Krankheitssymptome, sondern vorzugsweise in Berichten über die Vorgeschichte der Erkrankung und die ferneren Schicksale der Patienten zu suchen. Beides sind Capitel, welche ron Seiten der älteren Bearbeiter vielfach eine allzu geringe Berücksichtigung erfahren haben und erst später in ihrer Bedeutung voll gewürdigt worden sind. Von neueren Arbeiten, welche speciell wertvolle ätiologische Studien enthalten, seien hier nur die Aufsätze von Leber und Krahnstöyer ${ }^{1}$ ) und Ewetzky ${ }^{2}$ genannt. Was die Trage nach der Prognose anlangt, so führt sehon Fuchs über die Lücken des Materials in dieser Hinsicht gerechtfertigte Klage. In vielen Fällen fehlt eine Weiterbeobachtung der Patienten gänzlich, oder dieselbe erstreckt sich nur auf

A. Sarkome der Iris.

\begin{tabular}{|c|c|c|c|c|c|c|c|}
\hline $\mathrm{Nr}$ & $\begin{array}{c}\text { Name und } \\
\text { Jahr }\end{array}$ & 离 & $\stackrel{4}{\rightleftarrows}$ & $\frac{80}{3}$ & Anamaestusche Daten & $\begin{array}{c}\text { Status puesens gur Zeit } \\
\text { der Operation }\end{array}$ & $\frac{g}{\sqrt[3]{3}}$ \\
\hline 1. & $\begin{array}{l}\text { B. } 1882 . \\
\text { cof. H, Bauex } \\
\text { "Beiträge } \\
\text { zur Casuistik } \\
\text { der Irissax"- } \\
\text { kome". I. D. } \\
\text { Halle 83]. }\end{array}$ & w. & 7 & I. & 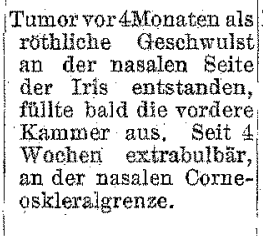 & $\begin{array}{l}\text { Kleinbohnengrosser Tumor von } \\
\text { graurothlichex Farbe ragt aus } \\
\text { der Iidspalte herror. Contrea } \\
\text { abgefacht und getrubt. } \\
\end{array}$ & IIT. \\
\hline
\end{tabular}

1) ,Ueber die bei Aderhautsarkomen vorkommende Phthisis des Augaptels und über die Bedeutung ron Verletzungen bei der Entstehung dieser Geschwülste.“ v. Graefe s Arch. f. Ophthalm. XLV. Bd. 1. Abth. S. 164 ff.

2) "Weitere Studien über intraoculare Sarkome" (II. Sarkome in atrophischen Augen). F. Graefe"s Arch. f. Ophthalm. XLV. Bd. 3. Abth. S. $563 \mathrm{ff}, 1896$. 
kurze Zeit nach der Operation, während Fuchs auf Grund seiner Erfahrungen eine Beobachtungszeit von mindestens fünf Jahren als sicheres Kriterium dauernder Heilung verlangt. Von weiteren Fragen, denen sich die Aufmerksamkeit der Autoren in den letzten Jahren in höherem Grade zugewandt hat, sind das Vorkommen von Phthisis bulbi bei Aderhautsarkom, das Verhältniss dieser Krankheit zur sympathischen Ophthalmie, die Dauer der Krankheit resp. ihrer einzeInen Stadien, sowie das Verhalten der Leukosarkome zu erwähnen. Selbstverständlich lassen sich dieselben nur auf Grund einer grösseren Statistik erörtern. In Folgendem sei es gestattet, die Beobachtungen der hiesigen Klinik ${ }^{1}$, die sich auf 100 Fälle beziehen und einen Zeitraum von mehr als 25 Jahren umfassen, zu diesem Zwecke zu verwenden. Zur Erleichterung der Uebersicht schicken wir eine Tabelle vorauf und schliessen uns weiterhin so weit als thunlich der Darstellungsweise von Fuchs an.

A. Sarkome der Iris.

\begin{tabular}{|c|c|c|c|c|}
\hline Tension & $\begin{array}{l}\text { Seh- } \\
\text { vermögen }\end{array}$ & Operation: & $\begin{array}{l}\text { Anatomische und histologische } \\
\text { Beschaffenbeit des Trmors }\end{array}$ & Spätere Nachrichten \\
\hline- & 0 . & Enucleation & $\begin{array}{l}\text { Massenhafte Riesenzellez in } \\
\text { Rundzellen mit feinem Reti- } \\
\text { culma eingebetet. Spariche } \\
\text { (physiologische) Pigmentzellen, } \\
\text { weite dunnwandige Gefásse. }\end{array}$ & Nach 16 Jahren gesund. \\
\hline
\end{tabular}

1) Die ältesten Fälle unserer Statistik entstammen der im Jahre 1885 erschienenen Dissertation von W. Martin, „Beiträge zur Prognostik der Uvealsarkome"; ein Theil derselben konnte von uns bis heute, resp. bis zu ibrem Tode weitex verfolgt werden, über einen anderen Teil waren spätere Mittheilungen nicht mehr zu erhalten. Acht der nachstehenden Beobachtungen hat Herr Geheimrath $\nabla$. H i p pel mir gütigst aus der Zeit seiner Thätigkeit in Giessen überwiesen. 


\begin{tabular}{|c|c|c|c|c|c|c|}
\hline $\mathrm{Nr}$. & $\begin{array}{c}\text { Name und } \\
\text { Jahr }\end{array}$ & 总 & $\frac{\dot{\Phi}}{4}$ & 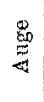 & Anamnestische Daten & $\begin{array}{l}\text { Status praeseas zur Zeit } \\
\text { der Operation }\end{array}$ \\
\hline 2. & $\begin{array}{l}\text { B. } 1892 . \\
\text { [of. K. Oenm- } \\
\text { Ixcb, Ueber } \\
\text { das Garkom } \\
\text { der Regen- } \\
\text { bogenhaut". } \\
\text { I. D. Halle. } \\
\text { g2]. }\end{array}$ & 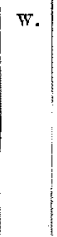 & 42 & R. & $\begin{array}{l}\text { Vor } 5 \% \text { Tahren ein } \\
\text { dunkelbraunes Pünkt- } \\
\text { chen in untern innern } \\
\text { Quadranten der Iris } \\
\text { entdeckt, das langsan } \\
\text { wuchs. Vor I Jabr } \\
\text { Blutung in die ror- } \\
\text { dere Kammer, seitdem } \\
\text { schnelleres Wahsthura } \\
\text { der Gesehwulst. }\end{array}$ & $\begin{array}{l}\text { Im untersten Teil der Iris dun- } \\
\text { kelgefarbter Tumor, der bis an } \\
\text { die Cormea heranreicht und } \\
\text { etwa Lrbsen-Grosse hat. } \\
\text {. }\end{array}$ \\
\hline
\end{tabular}

\section{B. Sarkome des Ciliarkörpers und der Chorioidea.}

I. Stadium.

\begin{tabular}{|c|c|c|c|c|c|c|}
\hline $\mathrm{Nx}$ & $\begin{array}{l}\text { Name and } \\
\text { Jahr }\end{array}$ & 迹 & 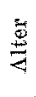 & $\underset{4}{g}$ & Anamuestisohe Daten & $\begin{array}{c}\text { Status praezens zur Zeir der } \\
\text { Operation }\end{array}$ \\
\hline 3. & St. 1874. & w. & 30 & P. & - & $\begin{array}{l}\text { Didnt an der Papille vine von der } \\
\text { Netzanat uberzogene, zienlich } \\
\text { genau abgegrenzte Gesch walst. }\end{array}$ \\
\hline 4. & L. 1870 . & W. & 28 & $?$ & $\begin{array}{l}\text { Sehstöruagen seit einigen } \\
\text { Monaten, }\end{array}$ & Ophuthalmoskopiseh Tumor. \\
\hline b. & B. 1876 . & 壮, & 68 & R. & $\begin{array}{l}\text { Bemerkt seit } 1 / g \text { Jahr } \\
\text { Gesichtsfeldeinschrän- } \\
\text { kung and Abnahme des } \\
\text { Visus. }\end{array}$ & $\begin{array}{l}\text { Gesichtsfelddefekt nach unten } \\
\text { innen. Der rothe Reflex des } \\
\text { Augenhintergrundes fehlt oben } \\
\text { aussen. }\end{array}$ \\
\hline 6. & a. 1878 & w. & 28 & $\mathbf{R}$ & - & $\begin{array}{l}\text { Fast totale Netzhautablosuag, an } \\
\text { einer Stelle eine besondere auf- } \\
\text { fallende Vorstülpung. }\end{array}$ \\
\hline 7. & N. 1882. & w. & 65 & R. & $\begin{array}{l}\text { Seit } 6 \text { Monaten Vermin- } \\
\text { derung des sehvermo- } \\
\text { gens, ab und zu } \\
\text { schmerzen. }\end{array}$ & $\begin{array}{l}\text { Zarte hintere Synechieen an der } \\
\text { nasalen Seite der Pupille; oph- } \\
\text { thalmoskopisch nach unten ein } \\
\text { scharf abgegrenzter dunkler } \\
\text { Buckel sichtbar. }\end{array}$ \\
\hline 8. & E. 1882 . & $\mathrm{m}$ & 60 & R. & $\begin{array}{l}\text { Sehstörung erst sett eini- } \\
\text { gen Wochen. }\end{array}$ & $\begin{array}{l}\text { Rothbrame Geschwulst won fmels } \\
\text { her bis fm Angenaze, etwa } \\
\text { kuglich hervorragend. Gesichts- } \\
\text { feld tach aussen und oben be- } \\
\text { schrankt. }\end{array}$ \\
\hline
\end{tabular}




\begin{tabular}{|c|c|c|c|c|}
\hline Tension & $\begin{array}{l}\text { Seh- } \\
\text { vermögen }\end{array}$ & Operation & $\begin{array}{l}\text { Anatomische und histologische } \\
\text { Beschaffenheit des Turaors }\end{array}$ & Spatere Nacurichten \\
\hline+ & $5 / 9$. & Iridekt. & $\begin{array}{l}\text { Spindelzellensarkom mit spar- } \\
\text { lichem Pigment und starken } \\
\text { Gefassen. }\end{array}$ & Nach 7 Jahren gesund. \\
\hline
\end{tabular}

B. Sarkome des Ciliarkörpers und der Chorioidea. I. Stadium.

\begin{tabular}{|c|c|c|c|c|}
\hline Tension & $\begin{array}{l}\text { Seh- } \\
\text { vermogen }\end{array}$ & Operation & $\begin{array}{l}\text { Anatomische und histologische } \\
\text { Beschaffenheit des Tumors }\end{array}$ & Spätere Nachrichten \\
\hline+ & $?$ & Enucleation. & $\begin{array}{l}\text { Pigmentirtes Chorieidealsar- } \\
\text { kom, flach in der Nahe des } \\
\text { Opticus entspringend, mit } \\
\text { erbsengrossem Hocker. Spin- } \\
\text { delzellen. }\end{array}$ & $\begin{array}{l}\text { Nach } 11 / 2 \text { Jahren an } \\
\text { Generalisation des } \\
\text { Tumors ohne örtliches } \\
\text { Recidiv } \uparrow \text {. }\end{array}$ \\
\hline+ & $?$ & Enueteation. & $\begin{array}{l}\text { Pigmentirtes sarlom dex chori- } \\
\text { oidea, breitbasig im hinteren } \\
\text { Bulbusabschnitt aufsitzend, } \\
\text { Spindelzellen. }\end{array}$ & Nach 10 Jahren gesund. \\
\hline- & $\begin{array}{l}\text { mit }+1 / 6 \\
\text { mühsam } \\
\text { Jg. } 1 \text { anf } \\
20 \mathrm{om}\end{array}$ & Enucleation. & $\begin{array}{l}\text { Kleinbohnengrosses Melano- } \\
\text { sarkom dicht am Opthicus, } \\
\text { dessen Faserung es zasam- } \\
\text { mendrängt. Rumdzellen. }\end{array}$ & Nach 9 Jahren gesund. \\
\hline+ & $\begin{array}{l}\text { Kalender } \\
\text { zahlen auf } \\
1 / 2 \mathrm{~m} \text {. }\end{array}$ & Enacleation. & $\begin{array}{l}\text { In der Gegend des Aequators } \\
\text { sitzendes, erbsengrosses, un- } \\
\text { gefarbtes Sarkom der Ader- } \\
\text { haut, mit einem kugligen Vor- } \\
\text { sprung in der Mitte der Ober- } \\
\text { fiache. Spindelzellen. Reich- } \\
\text { liohe Vascularisation. }\end{array}$ & $\begin{array}{l}\text { Nach } 12 \text { Jahren an } \\
\text {.Uteruskrebs" er- } \\
\text { krankt, } 1 \text { Tahr später } \\
\text { trotz Totalexstirpa- } \\
\text { tion }+ \text {. }\end{array}$ \\
\hline+ & 0 & Enucleation. & $\begin{array}{l}\text { Wenig pigmentirtes, aber stark } \\
\text { vaskularisirtes Chorioidealsar- } \\
\text { kom, mit seiner breiten Basis } \\
\text { denopticus grösstentheils taber- } \\
\text { deckend. Rundzellen. }\end{array}$ & $\begin{array}{l}\text { Nach } 31 / 2 \text { Jahren an } \\
\text { Magensarkom } t\end{array}$ \\
\hline+ & $\begin{array}{c}\operatorname{mit}+1 / 2^{0} \\
\text { zahlen auf } \\
\text { 5m. }\end{array}$ & Enucleation. & $\begin{array}{l}\text { Schwach pigmentirtes Chorioi- } \\
\text { dealsarkom, Spindelzellen. }\end{array}$ & $\begin{array}{l}\text { Nach 5 Jahren an Leber- } \\
\text { und Magenmeta- } \\
\text { stasen } \frac{t}{T+}\end{array}$ \\
\hline
\end{tabular}




\begin{tabular}{|c|c|c|c|c|c|c|}
\hline$N \mathbf{r}$ & $\begin{array}{l}\text { Name und } \\
\text { Jabr }\end{array}$ & 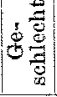 & $\frac{4}{4}$ & $\stackrel{5}{50}$ & Ancmnestische Daten & $\begin{array}{c}\text { Status praesens zux Zeit der } \\
\text { Operation }\end{array}$ \\
\hline 9. & Fr. 1888 & $W_{*}$ & 51 & L. & $\begin{array}{l}\text { Selsturung seit } 4-5 \mathrm{Mo} \\
\text { naten. }\end{array}$ & 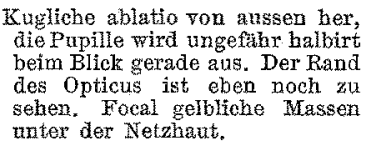 \\
\hline 10. & K. 1888 . & $\mathrm{m}$ & 58 & $\mathbf{L}_{*}$ & $\begin{array}{l}\text { Seit Uber 1 Jabr Abnahme } \\
\text { des Sehvermbgens. }\end{array}$ & $\begin{array}{l}\text { Etwa die ganze motere Netzhatat- } \\
\text { halfte abgelöst, schwappend. } \\
\text { Höckriger, brauner Tumor focal } \\
\text { zu sehen. Gesichtsfeld nur in } \\
\text { uatersten Drittel erhalten. }\end{array}$ \\
\hline 11. & B. 1888 . & $\mathrm{m}$. & 62 & $\mathbf{R}$. & $\begin{array}{l}\text { Verschlechterung des } \\
\text { Sehens seit } 10 \text { Monaten. } \\
\text { Gesichtsfeldbeschrän- } \\
\text { kung. }\end{array}$ & $\begin{array}{l}\text { Folral gelbgrau schimmernde pro- } \\
\text { minirende Scheibe an der aus- } \\
\text { seren Netzhathalfte. Ophthal- } \\
\text { moskopisch ablatio. Vordere } \\
\text { Kammer leicht abgeflacht, Pu- } \\
\text { pille starr. }\end{array}$ \\
\hline 12. & B. 1889 . & $\mathrm{m}$. & 47 & R. & Sehstorung seit $\% / 4 \mathrm{Jahr}$ & $\begin{array}{l}\text { Zwwei grössere und ein kleinerer } \\
\text { Knollen in der Tiefe zu sehen, } \\
\text { iberzogen rop der adhärenten } \\
\text { Netzhant, Puplle erweitert, } \\
\text { starr. }\end{array}$ \\
\hline 13. & Seh, 1889. & $\mathrm{~m}$ & 39 & L. & $\begin{array}{l}\text { Seit } 4 \text { Monaten Sehstö- } \\
\text { rung, sowie Flimmern } \\
\text { ror dem Auge. }\end{array}$ & $\begin{array}{l}\text { Ablatio retivae. Inter der abge- } \\
\text { losten Netzhaut Gefässe auf einem } \\
\text { dunkelgrauen Hintergrund. }\end{array}$ \\
\hline 14. & P. 1890. & फ. & 67 & L. & Seit Jahren Amaurose. & $\begin{array}{l}\text { Excessive Mropie, Dunkelgefärbte } \\
\text { ablatio. Habitus glaucomatosus. }\end{array}$ \\
\hline 5. & B. 1892 . & $\mathrm{m}$ & 66 & $\mathrm{R}_{\mathrm{q}}$ & $\begin{array}{l}\text { Komme mur wegen Brille, } \\
\text { hat nichts bemerlat. }\end{array}$ & $\begin{array}{l}\text { Naeh innen yon der Papille dunkle } \\
\text { Prominenz zait Gefiassen, von dex } \\
\text { adhärenten Netzhaut überzogen. }\end{array}$ \\
\hline 16. & U. 1892 . & W. & 44 & $\mathrm{H}_{*}$ & $\begin{array}{l}\text { Seit } 6 \text { Monaten Vermin- } \\
\text { derung des Sehvermö- } \\
\text { gens. }\end{array}$ & Tumor im Fundus sichtbar. \\
\hline 17. & G. 1892. & $w$. & 43 & $\mathbf{R}$. & $\begin{array}{l}\text { Seit } 1 \text { Jahr Abnahme des } \\
\text { Visus, seit } 5 \text { Monaten. } \\
\text { Amaurose. Niemals } \\
\text { Schmerzen oder Entzun- } \\
\text { dung. }\end{array}$ & $\begin{array}{l}\text { Ausserilich nichts Abnormes bis } \\
\text { auf eine etwas flache vordere } \\
\text { Kammer. Ophthalmoskopisch } \\
\text { Tumor. }\end{array}$ \\
\hline 18. & Sp. 1898. & $\mathrm{~m}$ & 64 & L. & $\begin{array}{l}\text { Sebstörung seit 7Monaten. } \\
\text { Vor } 1 / 2 \text { Jahr ablatio go- } \\
\text { funden, Tumor vermutet. }\end{array}$ & $\begin{array}{l}\text { Auge reizlos, grosse ablatio. Da- } \\
\text { runter dunkel durolischimmern- } \\
\text { der Tumor. }\end{array}$ \\
\hline
\end{tabular}


Beitrag zur Lehre yon den Chorioidealsarkomen.

\begin{tabular}{|c|c|c|c|c|}
\hline Tension & $\begin{array}{l}\text { Seh- } \\
\text { vermögen }\end{array}$ & Operation & $\begin{array}{l}\text { Anatomische und histologische } \\
\text { Beschaffenheit des Tumors. }\end{array}$ & Spätere Nachrichten \\
\hline n. & $\begin{array}{l}\text { Handbewe- } \\
\text { gungen peri- } \\
\text { pher (mir } \\
\text { unten und } \\
\text { aussen). }\end{array}$ & Enucleation. & $\begin{array}{l}\text { Kleines ungefärbtes Spindel- } \\
\text { zellensarkom, nach aussen vom } \\
\text { Ejutritt des Sehnerven. }\end{array}$ & $\begin{array}{l}\text { Nach } 101 / 2 \text { Jabren } \\
\text { gesund. }\end{array}$ \\
\hline 丹l. & $\begin{array}{c}\text { Zahlut } \\
\text { Finger. } \\
\text { (uur unten) }\end{array}$ & Enucleation. & Melanosarkom am hinteren Pol. & $\begin{array}{l}\text { Nach } 5 \% / 2 \text { Jahren an } \\
\text { Mretastasen in Leber } \\
\text { und Lunge } t \text {. }\end{array}$ \\
\hline+ & $\begin{array}{l}\text { Handbewe- } \\
\text { gungen } \\
\text { (nur } \\
\text { ausen). }\end{array}$ & Enucleation. & $\begin{array}{l}\text { Pigmentirtes Chorioidealsar- } \\
\text { kom, an der ausseren Bulbus- } \\
\text { halfte von der ora serrata } \\
\text { nach hinten ziehend. }\end{array}$ & - \\
\hline n. & 0 & Enucleation. & $\begin{array}{l}\text { Mrelanotisches Spindelzellensar- } \\
\text { kom der Chorioidea. }\end{array}$ & $\begin{array}{l}\text { Nach } 7 \text { Jahren (an } \\
\text { Herzlahmung) }+ \text { t. }\end{array}$ \\
\hline$?$ & $\begin{array}{l}\text { Finger in } \\
2 \mathrm{~m} \text { IIy. } \\
2, \tilde{\mathrm{D}} \mathrm{.}\end{array}$ & Enucleation. & $\begin{array}{l}\text { Melanosarkom im oberen Bul- } \\
\text { busabschnitt. }\end{array}$ & $\begin{array}{l}\text { Nach } 21 / 2 \text { Jahren an } \\
\text { Generalistion }+ \text {. }\end{array}$ \\
\hline $\begin{array}{l}\text { zwi- } \\
\text { schen } \mathbf{n} .\end{array}$ & 0 & Enucleation. & $\begin{array}{l}\text { Pigmentirtes Chorioidealsar- } \\
\text { kom. }\end{array}$ & $\begin{array}{l}\text { Nach } 5 \text { Jahren an } \\
\text { Ganeralisation }+\mathrm{t} \text {. }\end{array}$ \\
\hline n. & $\begin{array}{l}\operatorname{mit}+1 / 45 \\
S=5 / 8\end{array}$ & Enucleation. & $\begin{array}{l}\text { Kleines pigmentirtes Sarkom, } \\
\text { innen vom Optiens sitzend. }\end{array}$ & $\begin{array}{l}\text { Nach } 11 / 2 \text { Jahren an } \\
\text { Leber - and Magen- } \\
\text { metastasen } 1 \text {. }\end{array}$ \\
\hline$?$ & ? & Enucleation, & Pigmentirter Chorioidealtumor. & Nach 7 Jahren gesund. \\
\hline n. & 0 & Enucleation. & $\begin{array}{l}\text { Melanotisehes Chorioidealsar- } \\
\text { kom, im untern äussexn Qua- } \\
\text { dranten des yorderen Abschnit- } \\
\text { tes sitzend. Gefässreich. Spin- } \\
\text { delzellen. }\end{array}$ & $\begin{array}{l}\text { Nach 6 Jahren mit } \\
\text { gutem Erfolg wegen } \\
\text { Lebermelanosarkom } \\
\text { operirt. 3/4 Jahr spä- } \\
\text { ter noch gesund. }\end{array}$ \\
\hline n. & $\begin{array}{l}\text { Handbewe- } \\
\text { gungen in } \\
\text { der unteren } \\
\text { Gesichts- } \\
\text { feldhalfte. }\end{array}$ & Enucleation. & $\begin{array}{l}\text { Kirschikerngrosses Melanosar- } \\
\text { kom aahe dem Opticuseintritt. }\end{array}$ & Nach 3/4 Jahr gesund. \\
\hline
\end{tabular}


E. Pawel.

\begin{tabular}{|c|c|c|c|c|c|c|}
\hline $\mathrm{Nr}$. & $\begin{array}{c}\text { Name und } \\
\text { Jahr }\end{array}$ & 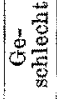 & $\stackrel{5}{\stackrel{5}{0}}$ & .00 & Anamnestische Daten & $\begin{array}{c}\text { Status praesens zar Zeit der } \\
\text { Operation }\end{array}$ \\
\hline
\end{tabular}

II. Stadium.

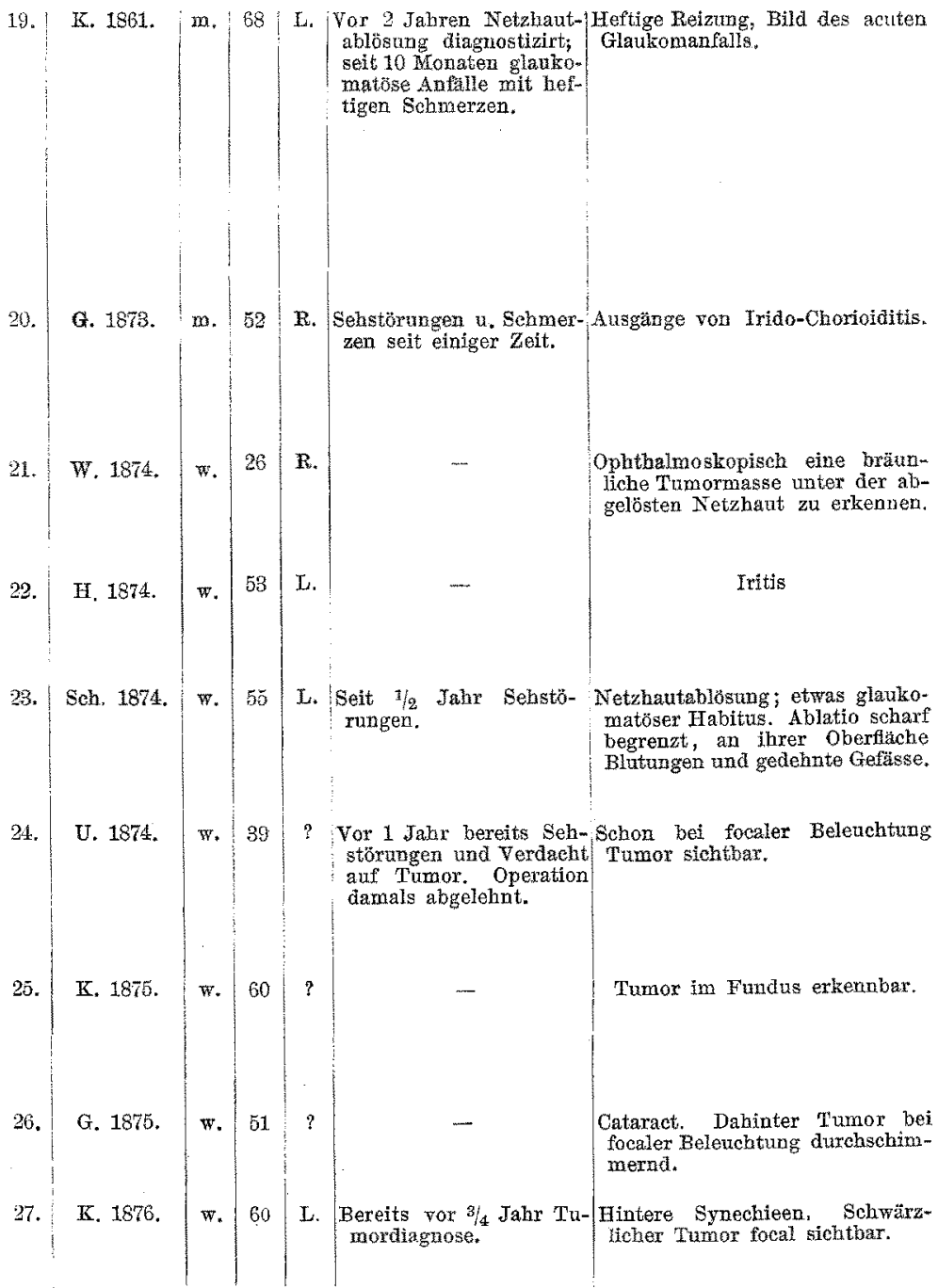




\begin{tabular}{|c|c|c|c|c|}
\hline Tension & $\begin{array}{l}\text { Seh- } \\
\text { vermögen }\end{array}$ & Operation & $\begin{array}{l}\text { Anatomische und histologische } \\
\text { Beschaffenheit des Tumors. }\end{array}$ & Spatere Nachrichten \\
\hline
\end{tabular}

\section{Stadium.}

\begin{tabular}{|c|c|c|c|c|}
\hline+ & 0 & Enuclettion. & $\begin{array}{l}\text { Fignentirtes Chorioidealsay- } \\
\text { kom. }\end{array}$ & $\begin{array}{l}\text { Nach der Enueleation } \\
29 \text {.ahre gestud ; im } \\
\text { 30. [1890] Melanosar- } \\
\text { kom der Orbita, vom } \\
\text { Enucleationsstumpf } \\
\text { ausgehend. Exent. } \\
\text { orbit. Der Sehnerv ist } \\
\text { bis zum For. opt. } \\
\text { schwarz, Rechts keine } \\
\text { Gesichtsfeldbeschrän- } \\
\text { kung. Weitere Nach- } \\
\text { rehten fehlen. }\end{array}$ \\
\hline+ & ? & Enueleation. & $\begin{array}{l}\text { Pigmentirtes, breitbasig aufsit- } \\
\text { zendes Chorioidealsarkom von } \\
\text { Haselnussgrosse mit einer Ein- } \\
\text { schnurung in der Mitte. Spin- } \\
\text { delzellen. }\end{array}$ & $\begin{array}{l}\text { Nack } 2 \text { Jahren an } \\
\text { Generalisation }+ \text {. }\end{array}$ \\
\hline+ & $?$ & Enucleation. & $\begin{array}{l}\text { Chorioideaisarkom, bohnen- } \\
\text { gross, bis an den opticus } \\
\text { heranreichend, nur teilweise } \\
\text { pigmeatre. Spundelzellen. }\end{array}$ & $\begin{array}{l}\text { Nach } 101 / 2 \text { Jahren } \\
\text { gestand. }\end{array}$ \\
\hline - & $\begin{array}{l}\text { Zahlt } \\
\text { Finger anf } \\
\text { I1/2 m. }\end{array}$ & Enucleation. & $\begin{array}{l}\text { Choriotdealsarkom mit vorzugs- } \\
\text { weise centraler Pigmentimung, } \\
\text { siob kegelformig erhebend, } \\
\text { Spindelzellen. }\end{array}$ & Nach 11 Jahren gesund. \\
\hline $\mathrm{n}$. & $\begin{array}{l}\operatorname{Mrit}+1 / 16 \\
\operatorname{Jg} .19\end{array}$ & Enucleation. & $\begin{array}{l}\text { Pigmentirtes Chorioidealsar- } \\
\text { kom ron. Elaselnussgrösse mit } \\
\text { einem ungefärbten kleineren } \\
\text { Vorsprung. Kleine Spindel- } \\
\text { zellen. }\end{array}$ & Nach 11 Jahren gesund. \\
\hline+ & 0 & Enueleation. & $\begin{array}{l}\text { Sol wa phignentirtes nussgros- } \\
\text { ses Chorioidealsarkom, bis an } \\
\text { die Linse heranreichend. Spin- } \\
\text { delzellen. }\end{array}$ & $\begin{array}{l}\text { Nach } 1 \text { Jahr wegen ort- } \\
\text { Hehen Recidivs Expis- } \\
\text { cer, nitwegname des } \\
\text { Periostes. } 1 / 4 \text { Jahr da- } \\
\text { raw an Generalisa- } \\
\text { tion }+ \text {. }\end{array}$ \\
\hline$?$ & $?$ & Enueleation. & $\begin{array}{l}\text { Bohnengrosses, breitbasig auf- } \\
\text { sitzendes Chorioidealsarkom } \\
\text { mit geringer Pigmentirung } \\
\text { und centraler Verfettung. } \\
\text { Spindelzellen. }\end{array}$ & $\begin{array}{l}\text { Nach } 3 \text { Jahren an } \\
\text { Generalisation } \frac{1}{1}\end{array}$ \\
\hline+ & & Enucleation. & $\begin{array}{l}\text { Pigmentirtes Choriodacalsar- } \\
\text { kom, full, den hinteren Bul- } \\
\text { busabschoitt. Spindelzellen. }\end{array}$ & Nach 10 Jabren gesuna. \\
\hline+ & $\begin{array}{l}\text { Talender- } \\
\text { zahlem in } \\
3 \mathrm{~m} .\end{array}$ & Enucleation. & $\begin{array}{l}\text { Kirschlerngrosses Melanosax- } \\
\text { kom der Ciliarkorpergegend, } \\
\text { die Stlera am Cornealfalz her- } \\
\text { rordrangend. Spindelzellen. }\end{array}$ & $\begin{array}{l}\text { Nach } 5 \text { Jahren an } \\
\text { Magenleiden } \dagger \text {. }\end{array}$ \\
\hline
\end{tabular}


E. Pawel.

\begin{tabular}{|c|c|c|c|c|c|c|}
\hline $\mathrm{Nx}$ & $\begin{array}{l}\text { Name und } \\
\text { Jahr }\end{array}$ & 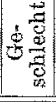 & 递 & 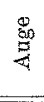 & Aramnestische Daten & $\begin{array}{c}\text { Status praesens zur Zeit der } \\
\text { Operation }\end{array}$ \\
\hline 28. & B. 1876 & $\mathrm{~F}:$ & 24 & L. & $\begin{array}{l}\text { Seit } 6 \text { Monaten Sehstö- } \\
\text { rang bemerit. }\end{array}$ & $\begin{array}{l}\text { Eabitus des ausseren Augas ganz } \\
\text { dem Bilde einer Epishleritis ent- } \\
\text { sprechend. Aufhebung der yor. } \\
\text { deren Kammer, brechende } \\
\text { Medien nacurchsichtig. }\end{array}$ \\
\hline 29. & ㅍ. 1876 . & w. & Gó & L. & - & $\begin{array}{l}\text { Iritis mit Cataracta incip. Er- } \\
\text { bebliche Gesichtsfeldbeschrän- } \\
\text { kung nach oben rechts. Peri- } \\
\text { pher difuse Chorioidealverande- } \\
\text { rungen. }\end{array}$ \\
\hline 30. & C. $187 \%$. & w. & 24 & R. & $\begin{array}{l}\text { Sehstörungen } a \text {. Schmer- } \\
\text { zen seit Monaten. }\end{array}$ & Tumor opthalmoskopiseh sichtbar. \\
\hline 31. & W. $187 \%$ & m. & $\widetilde{0} 2$ & $\mathbf{R}$. & - & $\begin{array}{l}\text { Sekundärglaukom. Diehte Glas- } \\
\text { körpertrubugen. }\end{array}$ \\
\hline 32. & I. 1878. & $\mathrm{~m}$. & 49 & $\mathbf{R}_{*}$ & $\begin{array}{l}\text { Vor }{ }^{1 / 2} \text { Jahr merlte Pat, } \\
\text { zafuhig, dass er mit dem } \\
\text { rechten Auge nur nach } \\
\text { der Aussenseite, und die } \\
\text { Hand soeben noch sohen } \\
\text { konnte. Schmerzen orst } \\
\text { in letzter Zeit. }\end{array}$ & $\begin{array}{l}\text { In den Glaskörper hinein ragt ein } \\
\text { deutlich abgrenzbarer Tumor mit } \\
\text { grauer Oberfläche. Flottirende } \\
\text { Netzhautablösung. Gesichtsfeld- } \\
\text { besehrilakung oben und innen. }\end{array}$ \\
\hline 33. & Sch, 1878. & พ. & 73 & $\mathrm{R}$. & - & $\begin{array}{l}\text { Bei Durchlenchtung Gefässe des } \\
\text { Tumors sichtbar: Gesichtefeld } \\
\text { nach anssen und oben beschräntat. }\end{array}$ \\
\hline 34. & Fr. 1879 & $\mathrm{~m}$. & 41 & L. & $\begin{array}{l}\text { Sehstörung seit } 8 \mathrm{Mo}- \\
\text { naten. }\end{array}$ & $\begin{array}{l}\text { Netzhautablösung, darunter Tu- } \\
\text { mor. Optiens hab verdeckt, Ge- } \\
\text { sichtsfeld feult oben und innen. }\end{array}$ \\
\hline 35. & H. 1879 . & $\mathrm{m}$. & 59 & $?$ & $\ldots$ & $\begin{array}{l}\text { Tumor schon bel seitlicher Be- } \\
\text { leuchtung sichtbar. }\end{array}$ \\
\hline 36. & Fr. 1880. & ma. & 22 & I. & $\begin{array}{l}\text { Verletzung in einem } \\
\text { Gisenbergwerk, wonach } \\
\text { Amaurose, yor } 7 \text { Jabren. } \\
\text { Seit } 3 \text { Jahren Vergrös- } \\
\text { serung des Auges. Nie } \\
\text { Behmerzen, bis erst in } \\
\text { der letzten Zeit. }\end{array}$ & $\begin{array}{l}\text { Bulbus in allen Dutehmessern } \\
\text { vergróssert und in der Aequa- } \\
\text { torialgegend wit unregelmässigen } \\
\text { Buckeln Fersehen. Cataracta } \\
\text { calcarea. }\end{array}$ \\
\hline $3 \bar{r}$. & D. 1880 . & $\mathrm{m}$. & 56 & $\mathrm{R}$. & $\begin{array}{l}\text { Vor } 2 \text { Monaten Hufichlag } \\
\text { auf das Auge. Darauf } \\
\text { Amantose, Phthisis, } \\
\text { Schmerzen. }\end{array}$ & $\begin{array}{l}\text { Bulbus rexkleinert, vordere } \\
\text { Kammer fiach. Unmittelbar hinter } \\
\text { der Liase graugelber Refex. } \\
\text { Atropin erweitert die Puplle } \\
\text { nicht, löst aber einen Schmerz- } \\
\text { anfall aus. }\end{array}$ \\
\hline 38. & E. 1880 . & w. & 42 & L. & $\begin{array}{l}\text { Unter beftigen Kopf- } \\
\text { schmerzen seit s Jahren } \\
\text { erblindet. Verlauf unter } \\
\text { gunehmender Einengung } \\
\text { des Gestchtsfeldes. }\end{array}$ & $\begin{array}{l}\text { Siarke Ciliarinjection. Vordere } \\
\text { Kammer aufgehoben, Myosis. } \\
\text { Vorgebuckelte Purillarmembran. } \\
\text { Van }\end{array}$ \\
\hline
\end{tabular}


Beitrag zur Lehre yon den Chorioidealsarkomen.

\begin{tabular}{|c|c|c|c|c|}
\hline Teusion & $\begin{array}{l}\text { Sell- } \\
\text { vermögen }\end{array}$ & Operation & $\begin{array}{l}\text { Anatomische und histologische } \\
\text { Beschaffenheit des Tumors. }\end{array}$ & Spätere Nachrichten \\
\hline+ & 0 & Enucleation. & $\begin{array}{l}\text { Flach ausgedehntes pigmentix } \\
\text { tes Sarlom der choriotiea, } \\
\text { bis an den Cilarkorper reichend, } \\
\text { stelienweis bis an die Iris, } \\
\text { Spindel- und Rundzellen. }\end{array}$ & Nach 9 Jahren gesund. \\
\hline$\frac{3}{1}$ & $\begin{array}{l}\text { Kalender- } \\
\text { zahlen in } \\
2 \mathrm{~m} \text {. }\end{array}$ & Enncleation, & $\begin{array}{l}\text { Seln wenig pignentirtes Cili- } \\
\text { arkörpersarkom. Spindelzellen. }\end{array}$ & - \\
\hline$\frac{1}{6}$ & 0 & Enucleation. & $\begin{array}{l}\text { Fast den ganzen Bulbus aus. } \\
\text { fullendes Chorioidealsarkom } \\
\text { mit starker Plgmentirung. } \\
\text { Spindelzellen. }\end{array}$ & Nach 22 Jahren gesund. \\
\hline+ & 0 & Enucleation. & $\begin{array}{l}\text { Melanosarkom der Chorioidea, } \\
\text { bohnengross, mit einem Ende } \\
\text { den Optiows aberdeckend. } \\
\text { Spindelzellen. }\end{array}$ & Nach 8 Jahren gesund. \\
\hline+ & $\begin{array}{l}\text { Zahlt milh } \\
\text { sam Finger } \\
\text { auf } 1 \mathrm{~m} \text {. }\end{array}$ & Enucleation. & $\begin{array}{l}\text { Sparrlich pigmentirtes Spindel- } \\
\text { zollensarkom der Chorioidea. }\end{array}$ & Nach 7 Jahren gesund. \\
\hline- & $\begin{array}{l}\text { Zăhlt } \\
\text { Finger aut } \\
1 / 2 \mathrm{~m}\end{array}$ & Enucleation. & $\begin{array}{l}\text { Bohnengrosses melanotisches } \\
\text { Sarkom. Spindelzellen. }\end{array}$ & - \\
\hline$?$ & $\begin{array}{l}\text { Grosse } \\
\text { Zahlen in } \\
2 \mathrm{~m}\end{array}$ & Enucleation. & $\begin{array}{l}\text { Schwach pignentixtes Chorioi- } \\
\text { dealsarkom, noch klein, von } \\
\text { der unteren Optiousgrenze } \\
\text { ausgehend. Spmdelzellen. }\end{array}$ & Nach 20 Jahren gesund. \\
\hline- & 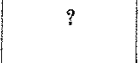 & Enucleation. & $\begin{array}{l}\text { Pignentirtes Sarkom des Corpas } \\
\text { cliare, innen ober. }\end{array}$ & Nach 6 Jahren gesund. \\
\hline $\mathrm{n}$. & 0 & Enucleation. & $\begin{array}{l}\text { Plgmentirtes Choriofdealsar- } \\
\text { kom, am ausseren Abschnitt } \\
\text { die sklera rorbuckelnd. }\end{array}$ & Nach 19 Jahren gesund. \\
\hline+ & 0 & $\begin{array}{l}\text { Operation } \\
\text { verwejgert }\end{array}$ & - & $\begin{array}{l}\text { Nach } 3 \text { Jahrea an } \\
\text { mehrmonatilcher } \\
\text { Lungenerkrankung }+ \text {. }\end{array}$ \\
\hline+ & 0 & Enucleation. & $\begin{array}{l}\text { Schwach pigmentintes Culiar } \\
\text { korpersarkom, in das Fupillar } \\
\text { gebiet hineinwucherad. Lux } \\
\text { irte Jinse, Excavation des } \\
\text { Opticus. Spindelzelen. }\end{array}$ & $\begin{array}{l}\text { Tod durch Selbstmord } \\
\text { nach 5y/a Janret; bis } \\
\text { dahin gesund. }\end{array}$ \\
\hline
\end{tabular}

v. Graefe's Archiv für Ophthalmologie. XLIX. 1. 


\begin{tabular}{|c|c|c|c|c|c|c|}
\hline Nr. & $\begin{array}{l}\text { Name und } \\
\text { Jabr }\end{array}$ & 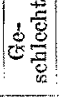 & $\frac{5}{5}$ & 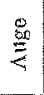 & Anamnestiscbe Daten & $\begin{array}{c}\text { Status praesens zur Zeit der } \\
\text { Operation }\end{array}$ \\
\hline 39. & B. 1881 . & $m$ & 64 & $\mathrm{~L}$. & $\begin{array}{l}\text { Tnfolge ron Netzhaut- } \\
\text { blutungen soll vor } 2 \\
\text { Jabren das sehvermoger } \\
\text { gesehwunden sein. } \\
\text { Sobmerzen seit } 2 \mathrm{Mo} \\
\text { Daten. }\end{array}$ & $\begin{array}{l}\text { Heftige Reizung des Auges mit } \\
\text { unregelmäsiger Pupillarerweim } \\
\text { texung. Acutes Secundatrglaukom. }\end{array}$ \\
\hline 40 & Sch. 1881. & w. & 27 & $\mathrm{~L}$ & 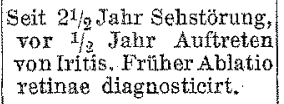 & $\begin{array}{l}\text { Secundärglaukom, heftige } \\
\text { Sohmerzen, Vordere Skleral- } \\
\text { ektasie. }\end{array}$ \\
\hline 41. & W. 1882. & m. & 28 & $\mathbf{R}$. & $\begin{array}{l}\text { Vor } 4 \text { Jahren Netzhaut- } \\
\text { ablosung constatirt; } \text { yor } \\
2 \text { Jahren soll nach hef- } \\
\text { tigem Erbrechen plotzlich } \\
\text { Amanroso eingetreten } \\
\text { sein. Schmerzen erst } \\
\text { in letoter Zeit. }\end{array}$ & $\begin{array}{l}\text { Aufgehobene rordere Kammer. } \\
\text { Pnpularman rarefieit. Catnmet, } \\
\text { Druckempfindlichlseit. }\end{array}$ \\
\hline 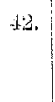 & W. 1882. & $\mathrm{~m}$. & 46 & I. & Seit $1 / 2$ Jahr Sebstörungen. & $\begin{array}{l}\text { Habitus glauconatosus. Atro- } \\
\text { phischer Opticus zwisehen 2. kug- } \\
\text { ligen Budungen. Cularinjection. } \\
\text { Schmerzen. }\end{array}$ \\
\hline 43 & H. 1882 . & $\mathrm{w}$. & 52 & R. & $\begin{array}{l}\text { Schmerzen seit einigen: } \\
\text { Woohen }\end{array}$ & $\begin{array}{l}\text { Nasal gelegene, getigerte Gem } \\
\text { selwwalst, blasige Netzhautab- } \\
\text { losung. Beim Bliek nach oben } \\
\text { normaler Reflex. Ausserlich gem } \\
\text { ringe Reizung. }\end{array}$ \\
\hline 44. & $\mathrm{Gr}, 1883$. & $\mathrm{m}$ & 60 & $\mathrm{R}$. & $\begin{array}{l}\text { Solt 1/8 Jahr Sehstörung, } \\
\text { seit z Monaten Entziti- } \\
\text { dung und Sohmerzen. } \\
\text { Sehen farbiger Ringe. }\end{array}$ & $\begin{array}{l}\text { Starke Fulung der Cinarvenen, } \\
\text { seichte vordere Kammer, weite } \\
\text { reactionslose pupille. Aus der } \\
\text { selben grangrumer Reflex. }\end{array}$ \\
\hline 45. & H. 1863. & $m$. & 58 & I. & $\begin{array}{l}\text { Schmerzlose Entwicke- } \\
\text { lung, Sebstorung erst } \\
\text { ror } 5 \text { Wochen bemerkt. }\end{array}$ & $\begin{array}{l}\text { Blasenformig rorgetriebenes kug- } \\
\text { liges Gebilde, all welohem Peti- } \\
\text { nalgefässe und Blatungen sicht- } \\
\text { bar sind, im äusseren Theil des } \\
\text { Augenhintergrundes. }\end{array}$ \\
\hline 46. & D. 1884 & w. & 31 & $\mathrm{P}$. & $\begin{array}{l}\text { Vor 1/s Jahr arzticher- } \\
\text { seits oy sticercus ver- } \\
\text { muthet. Sehr einge- } \\
\text { sehränktes Gesichtafeld } \\
\text { seit lingerer Zeit. }\end{array}$ & $\begin{array}{l}\text { Dicht am oberen Rand des Optiens } \\
\text { beginnende Ablatio. Nach oben } \\
\text { innen eine auffallende Vorbncke- } \\
\text { lung derselber. }\end{array}$ \\
\hline 47. & S. 1884 & $\mathrm{~m}$. & 54 & I. & $\begin{array}{l}\text { Seit I Jabr Yeminderung } \\
\text { des Visus. In den letaten } \\
\text { 14 Tagen hefthe Kopf- } \\
\text { scbmerzen. }\end{array}$ & $\begin{array}{l}\text { Tablus glancomatosus. Bei for } \\
\text { caler Beleuchtung wie bet durch } \\
\text { fallenden Lioht eine schwar } \\
\text { gefleckte Prorainenz unten anssen. }\end{array}$ \\
\hline 48. & St. 1884. & $m$. & 50 & L. & $\begin{array}{l}\text { Sehstorung seits Jahren, } \\
\text { Beginn wit Ausfall der } \\
\text { nusalen Gesichtsfeld- } \\
\text { hatate. }\end{array}$ & $\begin{array}{l}\text { Brtunliche Masse nichtweit binter } \\
\text { der Linse. Geringe Reizerschei- } \\
\text { nungen. }\end{array}$ \\
\hline
\end{tabular}


Beitrag zur Lehre von den Chorioidealsarkomen.

\begin{tabular}{|c|c|c|c|c|}
\hline Tension & $\begin{array}{l}\text { Seh- } \\
\text { vermogen }\end{array}$ & Operation & $\begin{array}{l}\text { Anatomische und histologische } \\
\text { Beseleffenheit des Tumors }\end{array}$ & Sputere Nachrichten \\
\hline+ & 0 & Enucleation. & $\begin{array}{l}\text { Haselnussgrosses pigmentirtes } \\
\text { Sarkon im hinteren Bulbus- } \\
\text { abscinitt. Epindelzellen. }\end{array}$ & $\begin{array}{l}\text { Nach } 21 / 4 \text { Jahren } \\
\text { plötzlich (an Herzpara- } \\
\text { lyse?) }+ \text {. }\end{array}$ \\
\hline+ & 0 & Enucleation. & $\begin{array}{l}2 \text { stark pigmentirte, zusammen } \\
\text { bängende Knollen im hinteren } \\
\text { Angenabschitt. Vorwiegend } \\
\text { Runczellen. }\end{array}$ & $\begin{array}{l}\text { Nach } 71 / 2 \text { Jahren an } \\
\text { Lebermetastased }+ \text {. }\end{array}$ \\
\hline+ & 0 & Enucleation. & $\begin{array}{l}\text { Stark pigmentirtes Chorioideal- } \\
\text { sarkom, vom inneren hinteren } \\
\text { Theil derAderhat ausgegangen, } \\
\text { fill das Bulbusinnere aus. } \\
\text { Spindelzellen. }\end{array}$ & $\begin{array}{l}\text { Wach } 51 / 2 \text { Tahren an } \\
\text { Metastasen in den Ab- } \\
\text { dominalorganen }+ \text {. }\end{array}$ \\
\hline+ & 0 & Enucleation. & $\begin{array}{l}\text { Gerade im himteren Pol des } \\
\text { Auges ein erbsengrosses, } \\
\text { glattes, rundes Melanosarkom } \\
\text { (8 mm Dml. Triehterformige } \\
\text { Ablatio. Rundzellen. }\end{array}$ & $\begin{array}{l}\text { Nach } 16 \% \text { Jahren } \\
\text { gesund. }\end{array}$ \\
\hline$\dot{m}$ & quant. & Enucleation. & $\begin{array}{l}\text { Pigmentirtes Sarkom vom in- } \\
\text { meren Aequatox aus in die } \\
\text { Ciliarkörpergegend hineingem } \\
\text { wuchert. Spindelzellen. }\end{array}$ & $\begin{array}{l}\text { Nach } 5 \text { Jahren an lang. } \\
\text { dauermder Iungenent- } \\
\text { zindung } \uparrow \text {. }\end{array}$ \\
\hline+ & \begin{tabular}{|} 
Etwas \\
Lichtschein \\
aber falsche \\
Projection.
\end{tabular} & Enucleation. & Chorioidealsarkom. & - \\
\hline n. & $\begin{array}{c}\text { Excentrisch } \\
\text { naeh aussen } \\
\text { werden } \\
\text { Finger ge- } \\
\text { zählt. }\end{array}$ & Enucleation. & $\begin{array}{l}\text { Hasemussgrosseg Lenkosarkom } \\
\text { in wnsseren Augenabsehnite, } \\
\text { reicht bis an die Linse heran. } \\
\text { Forwiegend Rundzellen. }\end{array}$ & $\begin{array}{l}\text { Nach } 1 y_{4} \text { Jahr an } \\
\text { Lebermetastasen }+ \text {. }\end{array}$ \\
\hline+ & 0 & Enncleation. & $\begin{array}{l}\text { Stark pigmentiertes Chorioin } \\
\text { dealsarkom, den oberen Theil } \\
\text { desopticus Hberdeckend. Rund- } \\
\text { zellen, wenig Spindelzellen. }\end{array}$ & Nach $11 / 2$ Jahr gesund. \\
\hline+ & 0 & Enucleation. & $\begin{array}{l}\text { Tnten aussen, djcht an den } \\
\text { Options heranreichend, ein } \\
\text { melanohisches, fast haselnuss- } \\
\text { grosses Sarkom. Rundzellen, }\end{array}$ & Nach 15 Jahren gesund. \\
\hline $\mathrm{n}$. & $\begin{array}{l}\text { Handbe- } \\
\text { wegungen } \\
\text { und Lieht- } \\
\text { schein nux } \\
\text { nach aussen } \\
\text { ind olen. }\end{array}$ & Enucleation. & $\begin{array}{l}\text { Nach aussen gelegener Chorioi. } \\
\text { dealtumor, dessen eine Hälfte, } \\
\text { dunkelpigmentirt und spindel } \\
\text { zellig, ron der anderen, unge- } \\
\text { harbten mond aus Rundzellen be- } \\
\text { stehenden, schar getrennt ist. }\end{array}$ & - \\
\hline
\end{tabular}




\begin{tabular}{|c|c|c|c|c|c|c|}
\hline $\mathrm{Nr}$. & $\begin{array}{l}\text { Name und } \\
\text { Jahr }\end{array}$ & 0 & $\stackrel{3}{2}$ & $\frac{9}{3}$ & Anamnestache Daten & $\begin{array}{c}\text { Status praesens zur Zeit der } \\
\text { Operation }\end{array}$ \\
\hline 49. & M. 1884. & $\mathrm{m}$. & 36 & L. & $\begin{array}{l}\text { Seit 11 Jahren Beein- } \\
\text { trachtigung der Sehliraft, } \\
\text { angeblich in Folge eines } \\
\text { Karbunkels am Orbital- } \\
\text { rand. Seit } 3 \text { Jahren } \\
\text { Amakurose, seit einigea } \\
\text { Monalen Sehmerzen. }\end{array}$ & $\begin{array}{l}\text { Cataract, Amaurose, skleral- } \\
\text { eztasie. }\end{array}$ \\
\hline 50 . & K. 1886 & W. & 28 & L. & - & $\begin{array}{l}\text { Tridochorioiditis, Secundarglau- } \\
\text { kom. Dunkler Reflex aus der } \\
\text { Pupille. Schmerzen. }\end{array}$ \\
\hline 51. & Sch. 1886. & $\mathrm{~m}$. & 46 & I. & $\begin{array}{l}\text { Sehvermögen seit } 1 \text { Jahr } \\
\text { sekr schlecht. Reizzam } \\
\text { stand erst seit lurzer } \\
\text { Zeit. }\end{array}$ & $\begin{array}{l}\text { Rauchiger Reflex aus der weiten, } \\
\text { träg reagierenden Pupille. Durch- } \\
\text { leuehtung unmöglich. Schmerzen. }\end{array}$ \\
\hline 52. & B. 1886. & W. & 51 & L. & - & $\begin{array}{l}\text { Ausgänge ron Iridocyclitis, Secur:- } \\
\text { därglaukom. }\end{array}$ \\
\hline 53. & H. 1886. & $\mathrm{~m}$. & 56 & R. & $\begin{array}{l}\text { Wach Strohhalmstoss } \\
\text { (vor } 3 \text { Jahren) langsam } \\
\text { entstandene Erblindung } \\
\text { ohne Schmerzen. }\end{array}$ & $\begin{array}{l}\text { Iritis. Ophthalmoskopisch suspec- } \\
\text { ter Refex vom Fundus auf der } \\
\text { lateralen Seite. }\end{array}$ \\
\hline 54 & Sp. $188 \%$ & $w$. & 62 & $\mathbf{R}$. & $\begin{array}{l}\text { Seit längerer Zeit Seh } \\
\text { störung. Sobmerzen erst } \\
\text { seit eingen lagen. }\end{array}$ & Tumor focal erkennbar. \\
\hline $5 \overline{.}$ & P. 1888. & $w$. & 57 & R. & $\begin{array}{l}\text { Seit 2 Jahren Iangsame } \\
\text { Abnahme des Visus ohne } \\
\text { Schmerzen. Erst seit } 3 \\
\text { Mionaten Schmerzen, } \\
\text { Schwindel und Erbrechen. }\end{array}$ & $\begin{array}{l}\text { Seclusio pupillae, Secundärglau- } \\
\text { kom. }\end{array}$ \\
\hline 56. & B. 1888 . & $\mathrm{w}$. & 63 & $L_{*}$ & $\begin{array}{l}\text { Seit } 1 \text { Jahr Cataracta } \\
\text { Incip. Seit } 6 \text { Monaten } \\
\text { Ablatio xetinae und } \\
\text { Ananose. In der letzten } \\
\text { Zout Schmerzen. }\end{array}$ & $\begin{array}{l}\text { Starke entzundiche Erschei- } \\
\text { Dringen. Glankom. }\end{array}$ \\
\hline 57. & B. 1888 . & $\mathrm{m}$. & 72 & L. & $\begin{array}{l}\text { Sehstörung seit längerer, } \\
\text { heftige Kopfschmerzen } \\
\text { in letzter Zeit. }\end{array}$ & $\begin{array}{l}\text { Bei focaler Beleuchtung braun } \\
\text { rother Reflex dicht hinter der } \\
\text { Linse. }\end{array}$ \\
\hline 68. & T. 1888. & $\mathrm{~m}_{*}$ & 57 & L. & $\begin{array}{l}\text { Vor } 4 \text { Woehen Regen- } \\
\text { bogenfarben, seit 8Tagen } \\
\text { Gchmerzen wnd Schwel- } \\
\text { lung. }\end{array}$ & $\begin{array}{l}\text { Bild des acuten Glaukomanfalls } \\
\text { in Vexbindung mbt intraovularer } \\
\text { Hamorrhagie. }\end{array}$ \\
\hline 59 . & Br. 1888. & W. & 34 & $\mathrm{I}$. & $\begin{array}{l}\text { Voy } 3 / 4 \text { Jabr Beschrän- } \\
\text { kung des Gesichtsfeldes } \\
\text { bemerlat. Schmerzen } \\
\text { erst seit einem Tage. }\end{array}$ & $\begin{array}{l}\text { Oedem der Conjunctiva bulbi et } \\
\text { palpebrarum. Der Chemose ent- } \\
\text { apricht in ibrem Sitz (vorzugs- } \\
\text { weise links unten) eine Netz- } \\
\text { bautablosumg. }\end{array}$ \\
\hline
\end{tabular}


Beitrag zur Lehre ron den Chorioidealsarkomen.

\begin{tabular}{|c|c|c|c|c|}
\hline Tenston & $\begin{array}{l}\text { Seh- } \\
\text { rermogen }\end{array}$ & Operation & $\begin{array}{l}\text { Anatomische uth histologisehe } \\
\text { Bescbaffenheit des Tumors }\end{array}$ & Spätere Nachrichten \\
\hline- & 0 & Enucleation. & Melanosartiom der Chorioidea. & Nach 1 Jahr gesund. \\
\hline+ & $?$ & Enucleation. & $\begin{array}{l}\text { Pigmentirtes Chorioidealsar- } \\
\text { kom. }\end{array}$ & $\begin{array}{l}\text { Nach } 11 \text { Jahren an } \\
\text { "Magenkrebs }{ }^{*}+\end{array}$ \\
\hline$t$ & $\begin{array}{c}\text { Nur noch } \\
\text { Cichtschein, } \\
\text { aber } \\
\text { schlechte } \\
\text { Locali- } \\
\text { sation. }\end{array}$ & Enncleation. & $\begin{array}{l}\text { Pigmentirtes Chorioidealsar- } \\
\text { kom. }\end{array}$ & Nuch 13 Jabren gesund. \\
\hline+ & $?$ & Enucleation. & Sarkom der Chorioidea. & Nach 13 Jahren gesund. \\
\hline+ & quant. & Enveteation. & Melanosarkon. & $\begin{array}{l}\text { Nach } 9 / / 2 \text { Jabren plötz- } \\
\text { lich (an Apoplexie?) }+ \text { T. }\end{array}$ \\
\hline+ & 0 & Enucleation. & $\begin{array}{l}\text { Pigmentirtes Sarkom der } \\
\text { Chorioidea. }\end{array}$ & $\begin{array}{l}\text { Nach } 7 \text { Jahren an } \\
\text { Lebersarkom } † \text {. }\end{array}$ \\
\hline+ & 0 & Enucleation. & $\begin{array}{l}\text { Melanotischer Chorioidealsar- } \\
\text { kom. }\end{array}$ & $\begin{array}{l}\text { Lebt nach } 11 \text { Jabren. } \\
\text { Seit 1/, Jahr magen- } \\
\text { leidend. }\end{array}$ \\
\hline$\frac{1}{2}$ & 0 & Enncleation. & Pigmentsarkom der Chortoidea. & $\begin{array}{l}\text { Nach } 6 \text { Jahren (an } \\
\text { Alterssehwache?) }+ \text {. }\end{array}$ \\
\hline+ & $\begin{array}{c}\text { Etwas } \\
\text { Lichtschein. }\end{array}$ & Enucleation. & Melanosarkom. & Nach 11 Jahren gesund. \\
\hline+3 & 0 & Enucleation. & $\begin{array}{l}\text { Pigmentirtes Sarkom der } \\
\text { Ciliarkorpergegend. }\end{array}$ & $\begin{array}{l}\text { Nach } 7 \text { Jahren an } \\
\text { Lebermetastasen } \div \text {. }\end{array}$ \\
\hline+ & $\begin{array}{c}\text { (Nur in der } \\
\text { unteren } \\
\text { Hafte des } \\
\text { Gesichts- } \\
\text { feldes) } \\
\text { Finger auf } \\
2 \mathrm{~m} \text {. }\end{array}$ & Ennoleation. & $\begin{array}{l}\text { Pigmentsanom in hinteren } \\
\text { Pol des Auges. }\end{array}$ & $\begin{array}{l}\text { Nach } 101 / 2 \text { Jahren } \\
\text { geswad. }\end{array}$ \\
\hline
\end{tabular}


玉. Pawel.

\begin{tabular}{|c|c|c|c|c|c|c|}
\hline$N$ & $\begin{array}{l}\text { Name und } \\
\text { Jahr }\end{array}$ & 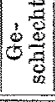 & $\frac{3}{8}$ & $\stackrel{8}{8}$ & Anamnestische Daten & $\begin{array}{l}\text { Status praesens zur Zoit der } \\
\text { Operation. }\end{array}$ \\
\hline 60. & F. 1889. & $\mathrm{~m}$. & 50 & L. & $\begin{array}{l}\text { Sehstörung nicht ke- } \\
\text { merkt Selt efnigen } \\
\text { Tagen plotzlich Schmer- } \\
\text { zen und linkseitige Mi- } \\
\text { gräne. }\end{array}$ & $\begin{array}{l}\text { Mässige Tnjection, vordere Kam- } \\
\text { mer aufgehoben, weite, starre } \\
\text { Pupile. Comea leicht getrübt, } \\
\text { Durchleuchtung tunnogglich. Bei } \\
\text { seitlicher Beleuehtang } 2 \text { kughiche } \\
\text { Erhabenheiten an der nasalen } \\
\text { Seite sichtbar. }\end{array}$ \\
\hline 61. & B. 1890 . & w. & 29 & L. & 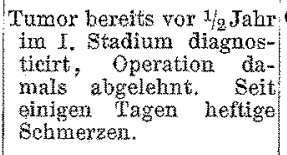 & 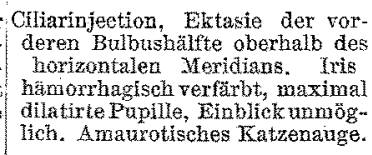 \\
\hline 62. & K. 1890 & m. & 47 & L. & $\begin{array}{l}\text { Seit uber 1 Jahx Seh- } \\
\text { störung, seit } 1 / 4 \text { Jahr } \\
\text { Amaurose, seits Wochen } \\
\text { Schmerzea ir der ganzen } \\
\text { linken Kopfluallfte. }\end{array}$ & $\begin{array}{l}\text { Starke Reizung. Iris vorgetrieben } \\
\text { und fast der Cornea anliegend. } \\
\text { Seichte vordere Kanmer. Bei } \\
\text { focaler Beleuchtnng grauer Re- } \\
\text { flex aus den Hintergrund, ron } \\
\text { einer kugligen Masse wusgehend. }\end{array}$ \\
\hline 63. & M. 1890 & $\mathrm{~m}$. & $?$ & $\mathbf{L}$. & Beginn vor $1 / 2$ Jahr. & $\begin{array}{l}\text { Injection der epislkleralen Venen } \\
\text { in derwnteren Bulbushaffte. Glau- } \\
\text { komatose Erscheinungen, Ablatio, } \\
\text { Unten in der Cilarkorpergegend } \\
\text { mehrene Knoten sichtbar. }\end{array}$ \\
\hline 64. & I. 1891. & $w$. & 66 & $\mathrm{R}$. & - & $\begin{array}{l}\text { Vordere fimmer tef, ringformige } \\
\text { Synechie. Graver Reflex binter } \\
\text { der Linse. }\end{array}$ \\
\hline 65. & J. 1891. & m. & 26 & R. & $\begin{array}{l}\text { Hochgradige Amblyopie } \\
\text { und Divergenzstellung } \\
\text { seit Kinaheit, seit } 6 \\
\text { Monaten völlige Erblin- } \\
\text { dung, seit einigen } \\
\text { Woohen. Schmerzen. }\end{array}$ & $\begin{array}{l}\text { Hamorrhagische Iritis, excen- } \\
\text { trische Pupille, Fundus nicht } \\
\text { deutlich zu erkenuen. Eíne Vor- } \\
\text { buckelung der Sklera nasalwärts. }\end{array}$ \\
\hline 68. & G. 1891 . & $\mathrm{m}$. & 38 & $R_{x}$ & $\begin{array}{l}\text { Alte Amaurose, seit eini- } \\
\text { gen Wochen Reizzustand. }\end{array}$ & $\begin{array}{l}\text { Conjunetivale Injeetion, Staphy- } \\
\text { loma selerae. Prominenz nasal } \\
\text { bei sellicher. Beleuchtung. }\end{array}$ \\
\hline 67. & P. 1891 . & $\mathrm{m}$. & 39 & R. & $\begin{array}{l}\text { Seit } 2 \text { Jahren Amaurose } \\
\text { mit Kopfschmerzen, vor } \\
1^{1 / 2} \text { Jahr Ablatio naeh } \\
\text { unten gefanden. }\end{array}$ & $\begin{array}{l}\text { Vollständige Netzhautablösung. } \\
\text { Nach mnen seitlich eine promi- } \\
\text { nirende Stelle derselben mit } \\
\text { graugelblichem schimmer. }\end{array}$ \\
\hline 68. & W. 1892 & W. & 45 & R. & $\begin{array}{l}\text { Seit } 2 \text { Monaten Erblin- } \\
\text { dung unter subjectiven } \\
\text { Lichterscheinungen. In } \\
\text { jüngster Zeit Sohmerzen } \\
\text { im Kopf and Arge. }\end{array}$ & $\begin{array}{l}\text { Cataract. Weite rerzogene Pu- } \\
\text { pille, sehx enge vordere Kammer. } \\
\text { Hinter der Linse aussen oben } \\
\text { ein verdachtiger Reflex. }\end{array}$ \\
\hline 69. & F. 1892 & $\mathrm{~m}$ & 54 & $\mathbf{R}$. & - & $\begin{array}{l}\text { Entzündheher Zustand, Habitus } \\
\text { glaucomatosus. Retina in scharf } \\
\text { geknickten Falten an die Hinter- } \\
\text { flahe der Linse gepresst. }\end{array}$ \\
\hline 70 & st. $18 \% 2$ & $\mathrm{ma}$ & 60 & $\mathrm{R}$. & $\begin{array}{l}\text { Abnahme des Visus seit } \\
2 \text { Jahren. }\end{array}$ & $\begin{array}{l}\text { Glaukomatöser Habilus. Dunkle } \\
\text { Prominenzen in den Glaskörper- } \\
\text { raum lineinragend }\end{array}$ \\
\hline
\end{tabular}


Beitrag zur Lehre ron den Chorioidealsarkomen.

\begin{tabular}{|c|c|c|c|c|}
\hline Tension & $\begin{array}{l}\text { Seh- } \\
\text { vermögen }\end{array}$ & Operation & $\begin{array}{l}\text { Anatomische und bistologisehe } \\
\text { Beschaffenheit des Tumors }\end{array}$ & Spätere Nachrichten \\
\hline+ & 0 & Enucleation. & $\begin{array}{l}\text { Melanotisches Sarkom in seit- } \\
\text { lichen wneren Bulbusabschnit. }\end{array}$ & $\begin{array}{l}\text { Nach } 91 / 2 \text { Jahren } \\
\text { gesund. }\end{array}$ \\
\hline+ & 0 & Enucleation. & $\begin{array}{l}\text { Leukotisches Ciliarkörpersar- } \\
\text { kom. }\end{array}$ & $\begin{array}{l}\text { Nach } 31 / 2 \text { Jahrea an } \\
\text { Lungenmetastasen }+ \text {. }\end{array}$ \\
\hline$\div$ & 0 & Enucleation. & $\begin{array}{l}\text { Gefässweiches, flaches Melano- } \\
\text { sarkom der Chorioidea, yom } \\
\text { lateralen Papllentande bis } \\
\text { ungefahr zum Aequator } \\
\text { reichend. Spindelzellen. }\end{array}$ & Nach 8 Jahren gesund. \\
\hline+ & 0 & Enueleation. & $\begin{array}{l}\text { Schwach pigmentirtes Sarkom, } \\
\text { vom Ciliarkörper nach hinten } \\
\text { reichend. }\end{array}$ & $\begin{array}{l}\text { Nach } 1 \text { Jahr an Leber- } \\
\text { metastasen }+ \text {. }\end{array}$ \\
\hline$p$ & 0 & Enveleation. & Kleines Melanosarkom. & - \\
\hline+3 & 0 & Enucleation. & $\begin{array}{l}\text { Seitlich nach innen sitzendes, } \\
\text { pigmentirtes Oborioidealsar- } \\
\text { Lom. }\end{array}$ & Nach 8 Jahren gesund. \\
\hline+ & 0 & Enucleation. & $\begin{array}{l}\text { Pigmentirtes Sarkom des } \\
\text { Cilarkôrpers. }\end{array}$ & Nach 6 Jahren gesund. \\
\hline+ & 0 & Enacleation. & $\begin{array}{l}\text { Pigmentirtes chorioidealsar- } \\
\text { kom etwas nasalwarts im } \\
\text { hinteren Absehnitt gelegen. }\end{array}$ & $\begin{array}{l}\text { Nach } 71 / 2 \text { Jahred } \\
\text { gesund. }\end{array}$ \\
\hline+ & 0 & Enneleation. & Sarkom der Chorioidea. & Nach 7 Jahren gesund. \\
\hline+ & 0 & Enucleation, & $\begin{array}{l}\text { Melanotisches Chorioidealsar- } \\
\text { kom. }\end{array}$ & - \\
\hline+ & 0 & Enucleation. & Melanosarcoma chorioideae. & Nach $41_{2}$ Jahren †. \\
\hline
\end{tabular}


E. Pawel.

\begin{tabular}{|c|c|c|c|c|c|c|}
\hline$N x$. & $\begin{array}{l}\text { Name und } \\
\text { Jahx }\end{array}$ & $\frac{1}{0}$ & 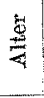 & 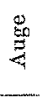 & Anamaestische Daten & $\begin{array}{c}\text { Status praesens zur Zeit der } \\
\text { Operation }\end{array}$ \\
\hline 71. & Gr. 18900. & m. & 58 & L. & $\begin{array}{l}\text { Seit } 2 \text { Jahren Abnahme } \\
\text { des Sehvermögens; ror } \\
14 \text { Tagen Sehmerzanfall } \\
\text { und. Amaurose. }\end{array}$ & $\begin{array}{l}\text { Starke Injection, Irisschlottern, } \\
\text { Luxatio lentis. Secundärglaukom. }\end{array}$ \\
\hline 72. & H. 1895. & $\mathrm{~m}$ & 63 & $\mathbf{L}$. & $\begin{array}{l}\text { Selt } 1 \text { Jahm Sehstorung, } \\
\text { Schmerzen seitsWueben. }\end{array}$ & $\begin{array}{l}\text { Bild des aenten Glankons. Druck- } \\
\text { empfindlichteit des corpus } \\
\text { ciliare. }\end{array}$ \\
\hline 78. & St. 1895. & $\mathrm{~m}$. & 58 & R. & $\begin{array}{l}\text { Seit } 6 \text { Jahren Amaurose, } \\
\text { seit } 8 \text { Tagen glaukoma- } \\
\text { tose Sehmerzen. }\end{array}$ & $\begin{array}{l}\text { Yordere Kammer aufgehoben, } \\
\text { Pupille weit, starr. Dicht hinter } \\
\text { der Linse eine reflectirende, } \\
\text { funde Prominenz. }\end{array}$ \\
\hline 74. & A. 1895 . & $\mathrm{m}$ & 51 & R. & $\begin{array}{l}\text { Sehstörung seit } 4 \text { Monaten } \\
\text { Schmerzen mid Entzhn- } \\
\text { dung seit } 5 \text { Wochen. }\end{array}$ & $\begin{array}{l}\text { Excentrische reactionslose } \mathrm{P}_{\mathrm{H}} \\
\text { pille. Im Hintergrum Tumor } \\
\text { nit Gefässnetz sichtbar. }\end{array}$ \\
\hline 75 & K. 1896. & $w$. & 70 & L. & $\begin{array}{l}\text { Unter heftigen linksseiti- } \\
\text { gen Kopfschwerzen all- } \\
\text { mählige Abnahme des } \\
\text { Visus seit } 2 \text { Jahren. }\end{array}$ & $\begin{array}{l}\text { Auge reizlos, starre mittelweite } \\
\text { Pupille. Cataract. Atrophische } \\
\text { Iris. Amaurose. Diagnose: } \\
\text { Glaucona absolutum. }\end{array}$ \\
\hline 76. & K. $189 \%$ & p. & 48 & L. & $\begin{array}{l}\text { Sehstorung seit } 1 \mathrm{Jahr} \\
\text { seit } 4 \text { Wochen Schmerzen. }\end{array}$ & $\begin{array}{l}\text { Starke Injection, vordere Kammer } \\
\text { fast aufgehoben. Pupille weit, } \\
\text { verzogen, reactionslos. Durch- } \\
\text { leuchtung uninöglich. }\end{array}$ \\
\hline $7 \pi$. & B. $189 \%$ & $\mathrm{~m}$. & 54 & L. & $\begin{array}{l}\text { Strohhalmverletzung ror } \\
\text { 4 Jahren, danach Aman- } \\
\text { rose und Phthisis. Beit } \\
14 \text { Tagen Sehmerzen. }\end{array}$ & $\begin{array}{l}\text { Bulbus stark verkleinert, Cornea } \\
\text { vollig abgefacht und graugetrinht. } \\
\text { Einblick in das Augeninnere un- } \\
\text { moglick. Druckempindlichkeit. }\end{array}$ \\
\hline
\end{tabular}

\section{Stadium.}

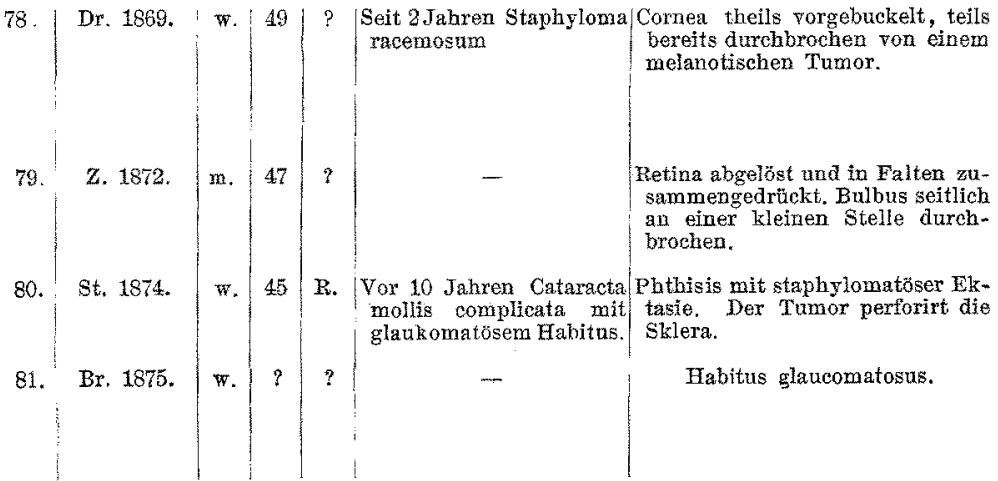


Beitrag zur Lehre von den Chorioidealsarkomen.

\begin{tabular}{|c|c|c|c|c|}
\hline Tension & $\begin{array}{c}\text { Seh- } \\
\text { vermögen }\end{array}$ & Operation & $\begin{array}{l}\text { Anatomische und histologische } \\
\text { Beschaffenheit des Tumors }\end{array}$ & Spätere Nachriehten \\
\hline+ & 0 & Enucleation. & $\begin{array}{l}\text { Lateral neben dem Opticusein- } \\
\text { tritt entspringendes haselnuss } \\
\text { grosses gpimdelzellensarlom } \\
\text { mit reichlikher Pigmentirung. }\end{array}$ & $\begin{array}{l}\text { Nach } 31 / 2 \text { Jabren } \\
\text { gesund. }\end{array}$ \\
\hline+ & $\begin{array}{l}\text { Unsicherer } \\
\text { Lichtschein, } \\
\text { keine Pro- } \\
\text { jection. }\end{array}$ & Enucleation. & Chorioldealsarkom. & Nach $1 / 4$ Jahr gesund. \\
\hline+ & 0 & Enucleation. & Sarkom der Chorioidea. & $\begin{array}{l}\text { Nach } 3^{1} / 2 \text { Jahren ge- } \\
\text { sund. }\end{array}$ \\
\hline+3 & 0 & Enucleation. & $\begin{array}{l}\text { Stark pigmentiries Spindel- } \\
\text { zellensarkom im hinteren Bul- } \\
\text { busabschnitt, zum grössten } \\
\text { Thell lateral rom opticusein- } \\
\text { tritt. Eine kleine flache Er- } \\
\text { hebung auf der nasalen Seite } \\
\text { der Papille. }\end{array}$ & $\begin{array}{l}\text { Nach } 31_{2} \text { Jabren ge- } \\
\text { sund. }\end{array}$ \\
\hline+ & 0 & $\begin{array}{l}\text { Iridektomie } \\
\text { und Cataract- } \\
\text { extraction. }\end{array}$ & $\begin{array}{l}\text { Stark pigmentirtes Sarkom, } \\
\text { ziemalich den ganzen hinteren } \\
\text { Bulbusabschnitt ausfüllend. } \\
\text { Spindelzellen. }\end{array}$ & $\begin{array}{l}\text { Nach } 5 \text { Tagen plötz- } \\
\text { lieher Tod an Apo- } \\
\text { plexie. Section exgiebt } \\
\text { Sarcoma chorioideae. }\end{array}$ \\
\hline+ & 0 & Enucleation. & $\begin{array}{l}\text { Gemischt pigmentirtes Spin- } \\
\text { delzellensarkom, das mit seiner } \\
\text { Basis vox lateralen Fapillen- } \\
\text { rande bis zur Aequatorgegend } \\
\text { reicht. }\end{array}$ & $\begin{array}{l}\text { Nach } 11 / 2 \text { Jahren ge- } \\
\text { sund. }\end{array}$ \\
\hline$?$ & 0 & Enucleation. & $\begin{array}{l}\text { Das ganze Bulbusinnere ron } \\
\text { einem spärlich pigmontirten } \\
\text { Chorioidealsarkom erfullt. } \\
\text { Rund- und Spindelzellen. }\end{array}$ & $\begin{array}{l}\text { Nach } 11 / 2 \text { Jahren ge- } \\
\text { sund. }\end{array}$ \\
\hline
\end{tabular}

\section{Stadium.}

Enucteation :

Mässig stark pigmentirtes

mit part. Chorioidealsarkom, welches

Exent. orbit.

den vorderen Bulbusabschnitt

Nach 5 Jahren an Geneansfiult und am inneren Cor-

ralisation + . Multiple

nealrand durchgebrochen ist.

Grosse Spindel- und Rundzelien.

Enucleation Melanosarkom der Choriotdea.

mit theilw. Spindel und Randzellen.

Exent. orbit.

Enucleation. Pigmentirtes Chorioidealsar kom. Spindelzellen.

Hautsarkome).

$$
\text { a. }
$$

Nach 1 Jahr örtliches Recidiv: Exent, mit Wegnahme des Periostes, + bald darauf.

Nach 1/a Jahr obne ortliches Recidt an Generalisation $\uparrow$.

Enucleation Bohnengrosses Chorioidealsar-Nach einigen Monaten und part. kom, melanowisch, dicht an an Generalisation $\stackrel{*}{-}$

Exvisc, orbit. Opticus entstanden und daselbst den Bulbus perforirend Spindelzellen. 


\begin{tabular}{|c|c|c|c|c|c|c|}
\hline$N x^{*}$ & $\begin{array}{l}\text { Name nad } \\
\text { Jahr }\end{array}$ & $\frac{1}{3}$ & 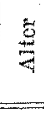 & $\frac{8}{m_{i}^{\infty}}$ & Aramaestische Daten & $\begin{array}{c}\text { Status praesens zar Zeit der } \\
\text { Operation }\end{array}$ \\
\hline 82. & K. 1876 & $\mathrm{~m}$ & 34 & $?$ & - & $\begin{array}{l}\text { Netzhautablusung, darunter } \\
\text { dunkler Tumor. }\end{array}$ \\
\hline 83. & $\begin{array}{l}\text { D. } 1880 . \text { [cf. } \\
\text { A. Wiegand, } \\
\text { J.D.Giessen } \\
\text { 88. Fall IT. }\end{array}$ & w. & 47 & I. & $\begin{array}{l}\text { Vor } 6 \text { Jahren Trauma. } \\
\text { Seit 2y Jahren Solmer- } \\
\text { zen, Entzitndung and } \\
\text { Abnahme des Sehver- } \\
\text { mogens, Seit } 7 \text { Wochen } \\
\text { Exophthalmus. }\end{array}$ & $\begin{array}{l}\text { Erbebliche Protrusion, Habitus } \\
\text { glancomblosus, Cataract. }\end{array}$ \\
\hline 84. & P. 1880 . & $\mathrm{m}$. & 67 & $\mathrm{~L}$. & $\begin{array}{l}\text { Vor } 17 \text { Jahreo plötzliche } \\
\text { Erblindung obne nach- } \\
\text { gewiesene Ursache. Seit } \\
7 \text { Jahren Phthisis. Seit } \\
\text { //2 Jahr sehmerzlos } \\
\text { wachsender Truor in } \\
\text { der Argenhohle. }\end{array}$ & $\begin{array}{l}\text { Grosse bläuliche Geschwulst in } \\
\text { oberen Theil der Orbita, von } \\
\text { Conjunctiva bedeckt. Mit int } \\
\text { zusammenbangend und zach } \\
\text { unten gedrängt der phthisische } \\
\text { Bulbus der mitsanut der Ge- } \\
\text { sehwulst noeh etwas in aer Orm } \\
\text { bita verschieblich ist. }\end{array}$ \\
\hline $8 \overline{.}$ & $\begin{array}{l}\text { Br. } 1880 . \text { [of. } \\
\text { A. Wiegand, } \\
\text { 1.c. FallII.] }\end{array}$ & w. & 58 & P. & $\begin{array}{l}\text { Seit } 7 \text { Jahren Erblindung } \\
\text { unter Schmerzen und } \\
\text { entzindlohen Zustanden. } \\
\text { Seit } 8 \text { Wochen beftige } \\
\text { Schmerzanfule. }\end{array}$ & 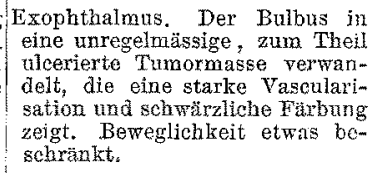 \\
\hline 86. & K. 1880. & $w_{*}$ & 64 & I. & $\begin{array}{l}\text { Gesichtsfeldbeschrän- } \\
\text { kxugg seit mehreren } \\
\text { Jahren. }\end{array}$ & $\begin{array}{l}\text { Opticusexcavation bds. L. Netz- } \\
\text { hatuablostung, an einer umi } \\
\text { sohriebenen prominenten stelle } \\
\text { von eigenthumlich dunklem Aus } \\
\text { sehen. }\end{array}$ \\
\hline 87. & J. 1882. & w. & $30 \tilde{~}$ & L. & $\begin{array}{l}\text { Selt 41/ Jahren Gesichts- } \\
\text { feldbeschränkang nach } \\
\text { oben, die in Folge eines } \\
\text { Stosses por das Auge } \\
\text { auftrat. Bald darauf } \\
\text { Glaukom und Cataract. }\end{array}$ & $\begin{array}{l}\text { Staphyloma sclerae nach innen } \\
\text { ron der Cornea. Zwischen dieser } \\
\text { nad dem Staphylom noch ein } \\
\text { kleiner subconjunctivaler pig- } \\
\text { mentirter Buckel. Sehnerzen. }\end{array}$ \\
\hline 88. & K.r.-C. 1888. & m. & 24 & I. & - & $\begin{array}{l}\text { Hoehgradig desorganisirtes Auge. } \\
\text { Totale Ablatio, Sklerektasieen, } \\
\text { Exophthalraus. Beweglichkeit } \\
\text { besonders nach oben bin sehr } \\
\text { behindert. }\end{array}$ \\
\hline 89. & K. 1884. & $\mathrm{w}$ & 61 & L. & $\begin{array}{l}\text { Sehstörung seit } 2 \text { Jahren. } \\
\text { Keine Schmerzen. }\end{array}$ & $\begin{array}{l}\text { Unregelmässig rerzervte Pupille, } \\
\text { vordere Kammer flach. Auf- } \\
\text { fallende Injection episkleraler } \\
\text { Gefüsse nach unten zu. }\end{array}$ \\
\hline 90. & M. 1885 . & W. & 50 & II. & $\begin{array}{l}\text { Seit 3/4 Jahr Amaurose. } \\
\text { Beginn der Sebstörung } \\
\text { por mindestets } 2 \text { Jahren. }\end{array}$ & 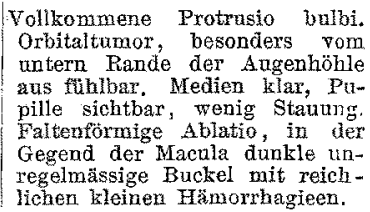 \\
\hline
\end{tabular}


Beitrag zur Lehre ron den Chorioidealsarkomen.

\begin{tabular}{|c|c|c|c|c|}
\hline Tension & $\begin{array}{l}\text { Seh- } \\
\text { vermögen }\end{array}$ & Operation & $\begin{array}{l}\text { Austomisohe und histologische } \\
\text { Beschafenbeit des Tumors }\end{array}$ & Spätere Nachrichten \\
\hline- & 0 & $\begin{array}{l}\text { Enucleation } \\
\text { mit part. } \\
\text { Exent. orbit. }\end{array}$ & $\begin{array}{l}\text { ATelanosarkom, das den hinteren } \\
\text { Bulbusabsehnitt ausfüllt, mit } \\
\text { linsengrossen extrabulbaren } \\
\text { Knoten nach innen vom op- } \\
\text { ticus, spindelzellen. }\end{array}$ & $\begin{array}{l}\text { Nach ot/2 Jahren ge- } \\
\text { sund. }\end{array}$ \\
\hline+ & 0 & Exent. orbit. & $\begin{array}{l}\text { Pigmentirtes Chorioidealsar- } \\
\text { kom am hinteren Pol mit } \\
\text { Propagation auf den Sehnerven. } \\
\text { Vorwiegend Rundzellen. }\end{array}$ & $\begin{array}{l}\text { Nach } 1 / 2 \text { Jahx in Folge } \\
\text { Reeldivs } t \text {. }\end{array}$ \\
\hline$?$ & 0 & Exent. orbit. & $\begin{array}{l}\text { Spirlich pigmentirtes, zell- } \\
\text { reiches Chorioidealsat wom mit } \\
\text { Perforationen nach hinten (bis } \\
\text { zum For. opt. Tumormassen) } \\
\text { und durch die Cornea. Rund- } \\
\text { zellen. }\end{array}$ & *i* nach $21 / 2$ Jahren \\
\hline etwas + & 0 & $\begin{array}{l}\text { Enucleation } \\
\text { mit part: } \\
\text { Exent. orbit. }\end{array}$ & $\begin{array}{l}\text { Ungleiehnässig pigmentirtes } \\
\text { Chorioidealsarkon, das den } \\
\text { gauzen Bulbus fillt. Perfo- } \\
\text { rationen an vorderen Pol und } \\
\text { an der inneren Seite des Aug- } \\
\text { aptels. Rund- und Spindel- } \\
\text { zellen. }\end{array}$ & $\begin{array}{l}\text { Nach } 1 \text { Jahr an Gene- } \\
\text { ralisation } \uparrow \text {. }\end{array}$ \\
\hline - & $\begin{array}{c}\text { Liest grosse } \\
\text { Zahlen in } \\
5 \mathrm{~m} .\end{array}$ & Enucleation. & $\begin{array}{l}\text { Wenig pigmentirtes spindel- } \\
\text { zellensarkom mit seitlicher } \\
\text { Perforation der Sklera an einer } \\
\text { kleinen Stelle. }\end{array}$ & $\begin{array}{l}\text { Nach 14. Jahren an } \\
\text { acuter Pneumonie } t \text {. }\end{array}$ \\
\hline- & 0 & Enueleation. & $\begin{array}{l}\text { Stark pigmentirtex Chorioideal- } \\
\text { tumor mit episkleralen Knoöt- } \\
\text { chen. Rund-und Spindelzellen. }\end{array}$ & $\begin{array}{l}\text { Nach } 2 \text { Janren an } \\
\text { Generalisation }+ \text {. }\end{array}$ \\
\hline- & 0 & $\begin{array}{l}\text { Enueloation } \\
\text { mit part. } \\
\text { Exent. orbit. }\end{array}$ & $\begin{array}{l}\text { Theilweise pigmentirtes Chori- } \\
\text { oidealsarlom, breitbasig am } \\
\text { hinteren Pole aufitzend, mit } \\
\text { extrabulbären wallnussgrossen } \\
\text { Knoten an dieser Stelle, Rund- } \\
\text { und Spindelzellen. }\end{array}$ & $\begin{array}{l}\text { Recidit rach } 2 \text { Jahren. } \\
1 / 2 \text { Jahr darauf an } \\
\text { Girnsarkom } \dagger .\end{array}$ \\
\hline n. & quant. & Enucleation. & $\begin{array}{l}\text { Kirschkerngrosses Melanosar- } \\
\text { kow in hinteren Augenab- } \\
\text { schnitt mit beginnender Per- } \\
\text { foration. Spindelzellen. }\end{array}$ & $\begin{array}{l}\text { Nach } 13 \text { Jabren an acu- } \\
\text { ter Lungenentzin- } \\
\text { dung }+ \text {. }\end{array}$ \\
\hline$?$ & 0 & Exent, orbit. & $\begin{array}{l}\text { Melanotisches Sarkom der } \\
\text { Chorioidea und Orbita. }\end{array}$ & $\begin{array}{l}\text { Nach } 1 / 4 \text { Jahr an Hirn- } \\
\text { sarkom th. }\end{array}$ \\
\hline
\end{tabular}


E. Pawel.

\begin{tabular}{|c|c|c|c|c|c|c|}
\hline $\mathrm{Nr}$. & $\begin{array}{l}\text { Name und } \\
\text { Jahr }\end{array}$ & 竞 & $\frac{2}{2}$ & $\stackrel{8}{\Xi}$ & Anamnestische Daten & $\begin{array}{c}\text { Status praesens zur Zeit der } \\
\text { Operation }\end{array}$ \\
\hline 91. & St. 1888. &. & 60 & $\mathrm{R}$. & - & $\begin{array}{l}\text { Starke entzündliche Reizung des } \\
\text { Anges, Concalrand dirchim } \\
\text { brochen von einem lleinen, } \\
\text { dunkeipigmentirten Zapfen. } \\
\text { Amanrose. }\end{array}$ \\
\hline 92 & Sch. 1888. & $\mathrm{~m}$ & 52 & L. & 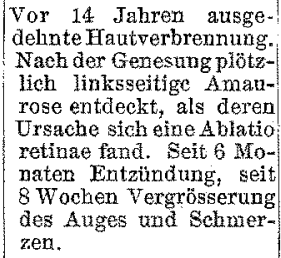 & $\begin{array}{l}\text { Dunkelrother, sehiefriger Tumor } \\
\text { umgiebt einen Theil der BuIbus- } \\
\text { peripherie. Cormea totaet und } \\
\text { durchsichtig. Beichte vordere } \\
\text { Kammer, Iris verwachsen. } \\
\end{array}$ \\
\hline 93. & $\ddot{0}, 1889$. & $m$. & 60 & I. & $\begin{array}{l}\text { Seit } 11 \text { Jahren Ablatio } \\
\text { uretinae. }\end{array}$ & - \\
\hline 91. & E. 1889. & \%. & 49 & L. & $\begin{array}{l}\text { Sejt } 3 \text { Jahren schmerz- } \\
\text { lose Erblindung. }\end{array}$ & $\begin{array}{l}\text { Hochgradige Protrusion und Dis- } \\
\text { location des Bulbus durch einen } \\
\text { dmimel pigmentirten Tumor. Im } \\
\text { Trmern des Auges prominente } \\
\text { Gesehwalstmassen. }\end{array}$ \\
\hline 95. & M 1890 & $w$. & 67 & P. & $\begin{array}{l}\text { Seit } 10 \text { Jnhren Frblin- } \\
\text { dung ohne xachweisliche } \\
\text { Ursache. Seit } 3 \text { Monaten } \\
\text { Protrusion und } \\
\text { Schmerzen. }\end{array}$ & $\begin{array}{l}\text { Bedentender Exophthalmus; in- } \\
\text { traocularer Tumor. } \\
\end{array}$ \\
\hline 96. & E. 1892 . & $\mathrm{m}$ & 56 & $\mathrm{R}$. & Erblindung seit 30 Jahren. & Focal-Tumor \\
\hline 97 & $1,1892$. & W. & 56 & I. & Sehstörung seit 1/a Jahr. & $\begin{array}{l}\text { Brumbincher Tumar in der Gegend } \\
\text { des Corpus ciliare unter der ab- } \\
\text { gelosten Netzhaut sichtbar. }\end{array}$ \\
\hline 98. & A. 1895 . & $w$. & 20 & L. & $\begin{array}{l}\text { Amaurose vor } 1 \text { Jahr au- } \\
\text { fallig entaleckt. Seit } \\
9 \text { Wochen Schmerzan- } \\
\text { fälle, seit } 8 \text { Tagen } \\
\text { Protrusion. }\end{array}$ & $\begin{array}{l}\text { Exophthalmus, Vordere Kammer } \\
\text { fach, reactionslose Pupille. Oph- } \\
\text { thalmoskopisch Ablatio und daw } \\
\text { runter Tumor. } z \text { extrabulbäre } \\
\text { Knoten. }\end{array}$ \\
\hline 99. & K. 1897. & W. & 37 & $\mathbf{R}$. & $\begin{array}{l}\text { Seit } 8 \text { Jahren Schlechter- } \\
\text { werden des Sehvermö- } \\
\text { gens. In letzter Zeit } \\
\text { Protrusion. }\end{array}$ & $\begin{array}{l}\text { Kleinapfelgrosser Tumor in der } \\
\text { Lidspalte bedeckt zum Theil den } \\
\text { nit ithm zusammenbängenden, } \\
\text { vergrösserten Bulbus. Armaurose }\end{array}$ \\
\hline 100. & F, 1898 & w. & 40 & $\mathbf{R}$. & $\begin{array}{l}\text { Schmerzen seit 3/4 Jahr. } \\
\text { Seit } 3 \text { Monaten Abnahme } \\
\text { der Sehkraft bis za } \\
\text { völliger Amazrose. }\end{array}$ & $\begin{array}{l}\text { Reizzustand des Auges, welte re- } \\
\text { actionslose Pupille. Eigenthüm. } \\
\text { licher Reflex aus derselben. } \\
\text { Durchleuchtung nicht moglich. }\end{array}$ \\
\hline
\end{tabular}


Beitrag zur Lehre ron den Chorioidealsarkomen.

\begin{tabular}{|c|c|c|c|c|}
\hline Tension & $\begin{array}{c}\text { Seb- } \\
\text { vermögen }\end{array}$ & Operation & $\begin{array}{l}\text { Anatomische und histologische } \\
\text { Beschaffenheit des Tumors }\end{array}$ & Spätere Nachrichten \\
\hline+ & 0 & Enucleation. & $\begin{array}{l}\text { Am Cornealrand perforizendes } \\
\text { Melanosarkom. }\end{array}$ & $\begin{array}{l}\text { Fach } 8 \text { Jahren }+ \text { Ur- } \\
\text { sache unbekannt. }\end{array}$ \\
\hline+ & 0 & Enucleation. & $\begin{array}{l}\text { Stark pigmentiries Chorioideal- } \\
\text { sarkom mit wallmussgrossem } \\
\text { extrabalbärem Knoten. }\end{array}$ & $\begin{array}{l}\text { Nach } 1 / 2 \text { Jahr an } \\
\text { Recidiv } T \text {. }\end{array}$ \\
\hline ? & ? & Enucleation. & $\begin{array}{l}\text { Pigmentirtes Chorioidealsar- } \\
\text { kom mit lieiner Perforationsm } \\
\text { stelle. }\end{array}$ & $\begin{array}{l}\text { Nach } 2 \text { Monaten Exent. } \\
\text { orbit wegen Recidivs in } \\
\text { der Orbita. + } 2 \text { Monate } \\
\text { spatter an Hirnsarkom. }\end{array}$ \\
\hline$\div$ & 0 & Exent orbit. & $\begin{array}{l}\text { Yasal entstaidenes melanom } \\
\text { tisches Chorioidealsarkom mit } \\
\text { breitem Durchbrueh in die } \\
\text { Orbita. }\end{array}$ & $\begin{array}{l}\text { Nach } 1 / 2 \text { Jahren an } \\
\text { Magenmetastasen }+\end{array}$ \\
\hline$?$ & 0 & $\begin{array}{l}\text { Exent, orbit. } \\
\text { [Da melano- } \\
\text { tische Massen } \\
\text { bereits in den } \\
\text { Knochen ge- } \\
\text { wachert sind, } \\
\text { am Opticusein- } \\
\text { eintritt nicht } \\
\text { ganz rein]. }\end{array}$ & $\begin{array}{l}\text { Melanotisches Chorioidealsar- } \\
\text { com, das den hinteren Ab- } \\
\text { schnitt des Bulbus füllt und } \\
\text { auf den Opticus resp. die } \\
\text { Orbita ubergegriffen hat. } \\
\end{array}$ & $\begin{array}{l}\text { Nach } 3 / 4 \text { Jahr an } \\
\text { Hirnsarkom } \dot{\leftarrow} \text {. }\end{array}$ \\
\hline$?$ & 0 & Enucleation. & $\begin{array}{l}\text { Pigmentirtes Ciliarkörpersar- } \\
\text { kom mit mehreren episkleralen } \\
\text { Perforationen. }\end{array}$ & - \\
\hline- & quant. & $\begin{array}{l}\text { Enucleation } \\
\text { mitt part. } \\
\text { Exent, orbit. }\end{array}$ & $\begin{array}{l}\text { Haselnussgrosses Melanosarkom } \\
\text { des Ciharkörpers nit. einem } \\
\text { linsengrossen episkleralen } \\
\text { Knoten am Aequator. Spin- } \\
\text { delzellen. }\end{array}$ & Nach 1 Jahr gesund. \\
\hline+ & 0 & Ennoleation. & $\begin{array}{l}\text { Zum Theil pigmentirtes Chori- } \\
\text { oidealsarkom im hinteren } \\
\text { Abschnitt. }\end{array}$ & $\begin{array}{l}\text { Nach } 4 y_{4} \text { Jahren ge- } \\
\text { sund. }\end{array}$ \\
\hline+ & 0 & Exent, orbit. & $\begin{array}{l}\text { Chorioidedsarkom mit Durch- } \\
\text { bruch in die Orbita, die es bis } \\
\text { zum Foramen opticum ausfüllt. }\end{array}$ & $\begin{array}{l}\text { Nach } 1 / 2 \operatorname{Jahr} \text { an } \\
\text { Generalisation }+\end{array}$ \\
\hline+3 & 0 & Exent. orbit. & $\begin{array}{l}\text { Choriotalalsarkom. An der } \\
\text { temporalen Seite neben dera } \\
\text { Aequaton eine Perforation. }\end{array}$ & Nach 1 Jahr gesund. \\
\hline
\end{tabular}




\section{Vorkommen und Einteilung der Uvealsarkome.}

Das Sarkom des Uvealtractus ist eine relativ seltene Erkrankung, die sich nach der Berechnung von Fuchs bei etwa 0,066 Proc. aller Augenkranken findet. Fuchs ${ }^{1}$ ) hält diesen Procentsatz eher für zu niedrig gegriffen, weil manche Fälle bei der Schwierigkeit der richtigen Diagnose in gewissen Stadien unter anderen Namen zur Registrirung kommen; eine vergleichende Zusammenstellung verschiedener" grösserer poliklinischer Berichte ergiebt folgende Zablen:

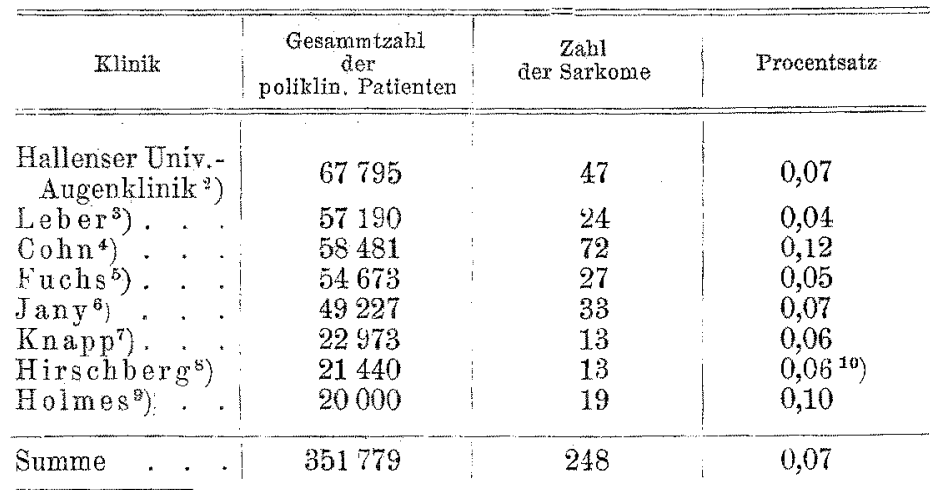

1) 1. c. p. 230 .

2) Bezieht sich auf einen Zeitraum von 14 Jahren, vom 1. April 1885 bis 1. April 1899.

3) Freudenthal, ซ. Graefe's Areh. f. Ophthalm. XXXYII. Bd. 1. Abth. 1891. Nach Leber und Krahnstöver, 1. c. p. 198, erklärt sich die Kleinheit dieses Procentsatzes ans der Thatsache, dass mur die operirten Fulle zu seiner Ermittelung verwandt wurden. Bei Berücksichtigung aller Falle kommt Leber zu der Zahl 0,05.

4) Rückblicke. Breslau 1897.

5) 1. c. p. 229 (von 1863 bis 1876).

6) Jahresbericht über die Augenklinik von 1875 bis 1888 . Von 1886 bis 1887 fortgefulht von Wolffberg. Breslau.

7) Alt, Klinischer Bericht über die Knapp sche Augenheilanstalt. Knapp's Arch. f. Augen- u. Ohrenheilkunde, VII. S. $395 \mathrm{ff}$.

8) ZurPrognose des Aderhautsarkoms. Virch. Arch. XC. S. 1 ff. 1882.

2) Knapp's Arch. VII. Bd. 2. Abth S. 301. 1868.

10) Hirschberg hat hier die Zahl 0,05; doch ergiebt die Berechnung, dass es 0,06 heissen muss. 
Die aus den Beobachtungen der hiesigen Klinik berechnete Ziffer ist also mit dem gefundenen durchschmitt. lichen Procentsatz identisch.

Die Erkrankung findet sich vorzugsweise im höheren Alter, wenngleich einzelne Fälle auch bei Kindern beschrieben sind. Namentlich disponirt sind, wie aus unserer Statistik herrorgeht, das 5. und 6. Lebensdecennium. Es fielen in die Jahre:

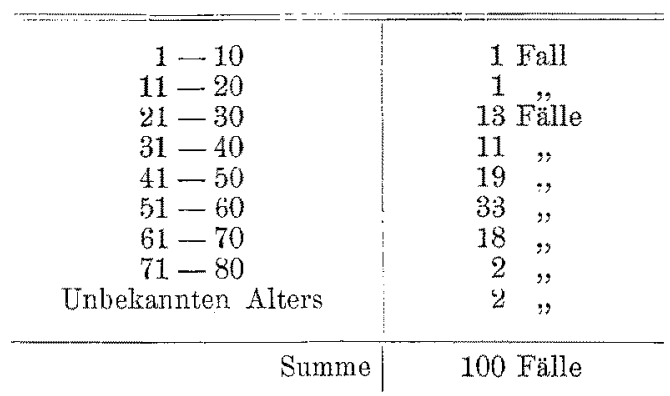

Das mittlere Lebensalter, aus allen Beobachtungen berechnê, beträgt 48,7 Jahre; das jüngste Individuum unserer Tabelle (Fall 1) war 7 , das älteste (Fall 33) 73 Jahre ait. Zu ähnlichen Resultaten kommen Fuchs und Hirschberg. Der erstere hat ein Durehschnittsalter von 44,2, Freudenthal ein solches von 49,4 Jahren; Law ford ${ }^{3}$ ) giebt hierfür die ziemlich hohe Zahl 58 an.

Beide Geschlechter sina annähernd gleichmässig betheiligt, wir funden unter den mitgeteilten Fällen 47 Männer und 53 Frauen. Die meisten älteren Statistiken lassen umgekehrt die Anzahl der männlichen Patienten überwiegen; Fuchs ermittelt ron 259 Beobachtungen nur $116=$ 44,75 Proc. weiblichen Geschlechts, Lawford vou 19 Fällen nur $5=26,3$ Proc., Freudenthal ${ }^{2}$ ) sogar nur p. 400 .

1) Cases of intraocular Sarcoma. Ophth. hosp. rep. XI, 4. 2) 1. c. p. 136 . 
20,4 Proc. Brière ${ }^{1}$ ) hat geglaubt, daraus eine besondere Dispositon des männlichen Geschlechtes zum Uvealsarkom ableiten zu können, eine Behauptung, die jedoch schon Fuchs ${ }^{2}$ ) entschieden zurťckgewiesen hat.

Fast ausnahmslos tritt die Erkrankung einseitig auf; ohne besondere Bevorzugung des rechten oder linken Auges. Bei unseren Fällen war

das rechte Auge

$43 \mathrm{mal}$,

das linke

48 , betroffen.

Eine Angabe der befallenen Seite fehlt in

$$
\text { Summe } 100
$$

Von den fünf doppelseitigen Fällen, deren Fuchs (S. 232) Erwähnung thut, beanstandet er selbst bereits zwei (Carter und Schiess), bei denen es sich wohl überhaupt nicht um Sarkom, sondern um eine entzündliche Hyperplasie, bezw. eine Iristuberkulose gehandelt hat. Die anderen drei (Landesberg, Dix on und Hirschberg) sind nicht völlig sichergestellt, am wahrscheinlichsten erscheint noch der letztgenannte:

Eine 56 jährige, durchaus gesunde Bäuerin hatte vor 7 Jahren zufällig entdeckt, dass ihr rechtes Auge blind geworden war, und sich dasselbe, als es vor einem Jahre begann sich zu vergrössem und herrorzutreten, enucleiren lassen. Die Untersuchung ergab ein weiches melanotisches Sarkom. Ein Jahr nach der Operation begann nun das linke Auge schlechter zu werden. Ophthalmoskopisch wie bei seitlicher Beleuchtung war in ihm eine grosse, gelbliche, mit stark injicirten Blutgefässen iberkleidete Geschwulst sichtbar, die, vom nasalen Theil des Ciliarkörpers ausgehend,

1) Léon Brière, Fitude clinique et anatomique sur les sarcomes de la choroide et sur la mélanose intraocul. Thèse de Paris 1873. p. 223.

g) 1. c. p. 231 . 
buckelförmig in den Glaskörperraum prominirte. Einen Monat später erblindete die Frau vollständig; eine Operation, sowie eine anatomische Untersuchung dieses Auges fand nicht statt. (Hirschberg, Knapp's Arch. X. Bd. S. 61 , Fall V.)

Der Ausgangspunkt des Tumors ist weitaus am häufigsten die Chorioidea, seltener der Ciliarkörper, am seltensten die Iris. Von Irissarkomen finden sich bisher nur 61 Fälle in der Literatur beschrieben, welche Ewetzky (,Weitere Studien über intraoculare Sarkome" IV., v. Graefe's f. Ophthalm. XLV. Bd. 3. Abth.) unter Zugrundelegung

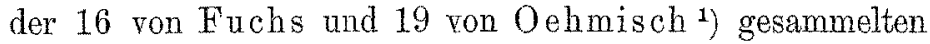
Fälle zusammengestellt hat. Unsere Beobachtungen vertheilen sich auf die drei Abschnitte der Urea in der Weise, dass zwei der Regenbogenhaut, 10 dem Corpus eiliare, die iibrigen 88 der Aderhaut angehören.

Was den anatomischen Bau betrifft, so sei hier nur kurz erwähnt, dass, wenn auch ziemlich alle Sarkomvarietäten in einzelnen Beobachtungen in der Uvea beschrieben worden sind, das Hauptcontingent von den spindel- und rundzelligen Formen gestellt wird. Die Pigmentirung, auf welche besonders von den älteren Autoren der grösste Werth bei der Classificirung intraoculärer Geschwülste gelegt wurde, gilt seit Virchow nicht mehr als das erste, wesentlichste Unterscheidungsmerkmal; Virchow. ${ }^{2}$ ) hat dargelegt, dass allein der histologische Bau die Natur einer Neubildung bestimme, und der Pigmentgehalt erst secundär zur: weiteren Charakterisirung in Betracht kommen kann. Immerhin ist es zweckmässig, die Eintheilung in gefärbte und ungefärbte Sarkome beizubehalten, weil die letzteren manche Figenthümlichkeiten und Besonderheiten aufweisen $\left.{ }^{3}\right)$.

1) K. Oemisch, Ueber das Sarkom der Regenbogenhant. Inang.m Diss. Hallo 1892.

2) R. Virchow. Die krankhaften Geschwülste. II. Bd. S. 185.

3) Sie sind auch für die Bestimmung derjenigen Schicht der v. Graefe's Arehiv fur Ophthalmologie. XLIX. 1. 
Schon bezüglich des Ortes der Entstehung ergiebt sich ein bemerkenswerther Unterschied, den bereits Fuchs hervorhebt; während nämlich die Mehrzahl der Sarkome sich in hinteren Abschnitt der Uvea zu entwickeln pllegt (Fuchs, 1. c. S. 166), bevorzugen die ungefärbten oder schwach pigmentirten die vorderen Theile derselben. So betrafen von den mitgetheilten 100 Fällen

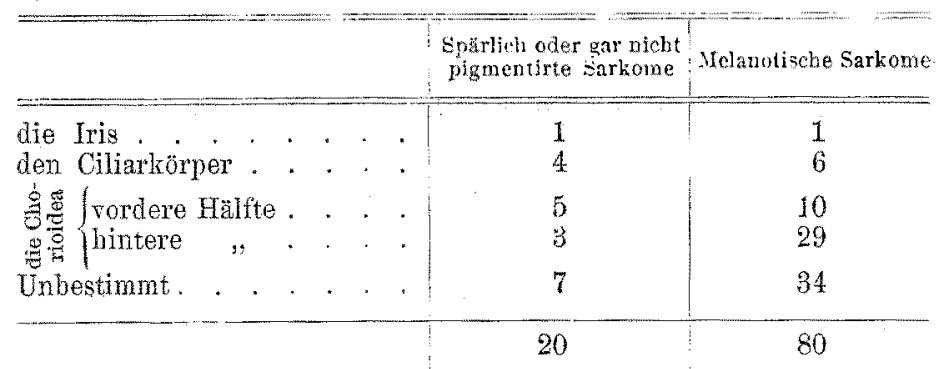

also eine ganz evidente Affinität der Leukosarkome zum vorderen, der Melanosarkome zum hinteren Augenabschnitt.

Während ferner bei den Melanosarkomen die Spindelzellen weitaus überwiegen, halten sich bei den ungefärbten Sarkomen die spindelzelligen und rundzelligen Formen ungefähr das Gleichgewicht. Fuchs zählt:

\begin{tabular}{c|c|c}
\hline & Spindelzellensarkome & Ruzdzellensarkome \\
\hline unter 229 Melanosarkomen : & 62 & 39 \\
"30 Leukosarkomen : & 13 & 12
\end{tabular}

Unsere Zahlen, die zwai zu klein sind, um als beweisend zu gelten, schliessen sich diesem Verhalten voll-

Aderhaut, ans welcher die Sarkome ihren Ursprung nohmen, von Bedeutung geworden. Während Fuchs alle Sarkome aus den tiefen Lagen der Chorioidea entstehen lässt, hat Sohieck (v. Graefe's Arch. f. Ophthalm. XLV. Bd. 2. Abth. S.433) durch seine Untersuchungen für die von Knapp und Brière aufgestellte Vermuthung, dass die Leukosarkome der Choriocapillaris entstammten, den anatomischen Beweis erbracht. 
ständig an; von 88 Melanosarkomen enthalten 30 Spindelzellen und nur 8 sind Rundzellensarkome, dagegen sind unter den 5 rein leukotischen Tumoren der Tabelle 2 Spindelzellen- und 2 Rundzellensarkome. Besonders lehrreich ist in dieser Beziehung Fall 45, bei welchem sich die eine dunkelpigmentirte Hälfte der Geschwulst scharf von der" anderen, ungefärbten, abhob. Die erstere erwies sich unter dem Mikroskop als aus Spindelzellen bestehend, die letztere zeigte dichtgedrängte kleine Rundzellen.

Eine weitere Eigenthümlichkeit der Leukosarkome ist ihr Vorkommen in relativ jugendlichem Lebensalter. Während das durchschnittliche Alter unserer gesammten Fälle 48,7, das unserer Melanosarkome 49,4 Jahre beträgt, ergiebt sich für die fünf ungefärbten Geschwiilste ein Mittel von 34,6 Jahren: Unter den letzteren befinden sich ferner 3 Patienten unter 30 Jahren, also mehr als die Hälfte, unter den 74. Melanosarkomen mit bekanntem Alter dagegen nur 10, d. h. noch nicht der siebente Theil. Daraus folgt zugleich, dass gerade die Sarkome der vorderen Uvealtheile, die ja, wie oben betont, häufig leukotischer Natur sind, bei relativ jugendlicheren Personen beobachtet werden müssen, als die im hinteren Bulbusabschnitte sich entwickelnden, und in der That hat schon Fuchs (S. 231) für die Sarkome der Iris ein durchschnittliches Alter von 31 Jahren ermittelt.

Bezüglich des Geschlechts theilen sich unsere Fälle folgendermaassen ein:

\begin{tabular}{|c|c|c|}
\hline & Männer & Frauen \\
\hline $\begin{array}{l}\text { Leukosarkome. } \\
\text { Melanosarkome }\end{array}$ & $\begin{array}{r}1 \\
35\end{array}$ & $\begin{array}{r}4 \\
40\end{array}$ \\
\hline
\end{tabular}

Bei der geringen Zahl unserer Beobachtungen lässt sich jedoch dieses ungewöhnliche Vorwiegen des weiblichen Geschlechts unter den Leukosarkomen wohl als zufällig deuten, 
zumal da andere Statistiken dasselbe nichtbestätigen. Wohlaber wird ibereinstimmend von allen Autoren iiber Irissarkome ein ähnliches Mehrheitsverhältniss der weiblichen Fälle angegeben; indess scheint es bisher nicht am Platze, daraus irgend welche Schliusse zu ziehen.

\section{Aotiologie.}

Wie die Entstehungsursache der Geschwiulste überhaupt, liegt die Aetiologie der Aderhautsarkome bisher noch völlig im Dunkeln; mit verschwindenden Ausnahmen lassen sich für ihr Auftreten gar keine stichhaltigen. Veranlassungen anfithren.

Eine Vererbung, wie sie für manche Geschwulstarten seit langem bekannt ist, ist hier noch in keinem einzigen Falle constatirt worden, trotz eingehender Nachforschungen namentlich ron seiten englischer Autoren. Dagegen liess sich bei manchen Patienten eine ,individuelle Disposition" annehmen, indem entweder anderweitige Pigmentanomalieen an irgend einer Körperstelle vorhanden waren, oder die Sarkome sich direct aus lange bestehenden, zum Theil angeborenen Pigmentflecken der Iris entwickelten. Von diesem letzteren Vorkomniss erwähnt Oemisch in seiner Dissertation.') 8 Beobachtungen, für die damals bekannten 35 Fälle von Irissarkom also einen immerhin bemerkenswerthen Procentsatz. Diese Angaben, die sich gewiss bei sorgfältiger Nachforschung noch vermebren und fernerhin bestätigen lassen, sind in der That sehr geeignet, die Frage nach der Entstehung der Uvealsarkome im Cohnheimschen Sinne dahin zu beantworten, dass mindestens ein. Theil derselben aus präexistirenden Keimen, also besonderen embryonalen Geschwulstanlagen, seinea Ursprung nimmt, in manchen Fällen angeregt durch irgend welche gelegentlich auf sie einwirkenden Reize.

i) Loc. cit. S. 24. 
Unter solchen Gelegenheitsursachen, welche den Anstoss zur Sarkomentwickelung geben kömnen, nehmen langdaternde Entzündungen die erste Stelle ein. Schon Virchow statuirt zwischen beiden Processen einen causalen Zusammenhang, indem er sagt ${ }^{1}$ ): „Aber sicher muss doch ein krankhafter Reiz der Geschwulstbildung vorangegangen sein, und dass dieser in vorausgegangenen entzündlichen Vorgängen gesucht werden darf, erscheint mir im Zusammenhalt aller ätiologischen Erfahrungen wohl berechtigt." Es sind denn auch in der Folge eine ganze Anzahl von Füllen beschrieben worden, die das Auftreten von Aderbautsarkom nach heftigen Entzündungen, meist einer Iridocyclitis mit Ausgang in Atrophie des Bulbus beweisen sollten. Da es indess heut keinem Zweifel mehr unterliegen kann, dass in manchen dieser Beobachtungen umgekehrt ein anfangs unbemerkt gebliebener Tumor die Veranlassung zu einer scheinbar spontanen Iridocyclitis mit nachfolgender Atrophie gewesen und erst nach Ablanif dieser Vorgänge zur Entdeckung gekommen war, wird man zur Beweisführung nur solche Fälle zulassen dürfen, in denen ein derartiges Verhalten absolut auszuschliessen und eine thatsächliche anderweitige Ursache der primären Entzündung mit Sicherheit nachzuweisen ist. Es liegt auf der Hand, dass es sich dabei so gut wie ausschliesslich um Verletzungen handeln wird, und von diesem Moment an fällt daher die Frage mit der Hypothese von der traumatischen Entstehung der Geschwülste zusammen. Man hat früher die Bedeutung von Traumen in dieser Hinsicht stark überschätzt, indem man annahm, dass sie als alleinige Ursache zur Entwickelung von Tumoren geführt hätten. Spräche nicht der ganze Zusammenhang des Capitels dagegen, so könnte man beinahe glauben, dass auch Fuchs sich dieser Meinung anschlösse, wenn er zu obigem Thema folgendes

1) Loc. cit. II. Bd. S. 249. 
bemerkt: "Auf welche Weise führt eine Verletzung zur Entwickelung eines Sarkoms? Die nächste Folge der Verletzung ist in der Regel eine heftige Entzündung, welche mit reichlicher zelliger Infiltration des Cvealtractus einhergeht und sehr oft mit Phthise des Bulbus endigt. Da solche Entzündungen sehr lange zu dauern pflegen und hänfige Nachschube machen, so bleibt auch die zellige Infiltration der Augenhäute durch lange Zeit bestehen und kann endlich zu einer danernden Verbildung derselben einer Hyperplasie führen. Man findet die Aderhaut so reichlich von Rundzellen und aus diesen hervorgegangenen Spindelzellen durchsetzt, dass die Aehnlichkeit mit einer diffusen, sarkomatösen Entartung eine vollkommene ist. In der That sind ja auch Verwechselungen zwischen beiden Zuständen vorgekommen. Anatomisch ist nun von der entzündlichen Hyperplasie zum Sarkom nur ein ganz kleiner Schritt." (1. c. p. 236.)

Die oben präcisirte Anschauungsweise erhielt einen Vertreter, der es unternahm, sie durch statistische Belege zu stïtzen, in Boll. Derselbe ${ }^{1}$ ) fand unter 344 in der Langenbeck'schen Klinik operirten Carcinomen $42=$ 12 Proc. traumatischen Crsprungs, und betrachtete diese Feststellung als einen Beweis fir die angefuhrte Theorie. Auch Cohnheim ${ }^{2}$ ) berechnete ron den in der Berliner Klinik innerhalb eines Jahrzehnts beobachteten Geschwülsten 14,3 Proc. als nach Verletzung entstanden, aber im Gegensatz zu Boll folgerte er daraus nicht, dass Traumen die vornehmlichste Ursache der Geschwulstentwickelung darstellten, sondern dass sie im Gegentheil bei diesem Vorgang eine höchst untergeordnete Rolle spielen müssten, da die eigens darauf gerichtete Untersuchung in 85,7 Proc. nicht den geringsten Anhaltspunkt für ein voraufgegangenes

1) Princip des Wachsthums. Berlin 1876.

2) Vorlesungen äber Allg. Pathologie. Berlin 1877. Bd. I. S. 632. 
Trauma hatte erbringen können. Berechnet man gar statt des Procentsatzes der traumatischen Geschwilste den verschwindenden Bruchtheil der Verletzungen, nach welchen in der Folgezeit ein Tumor sich bildete, so wird man unbedingt mit Cohnheim noch weitere ätiologische Momente neben dem Trauma verlangen, denn anderenfalls wäre es in der That nicht einzusehen, warum gerade in diesen seltenen Ausnahmefällen die Verletzung eine Neubildung verursacht haben soll, in zahllosen anderen und schwereren Fällen degegen nicht. Auf Grund dieser Erwägungen wird man den Traumen bei der Entstehung der Geschwülste nur die Bedeutung eines veranlassenden Momentes beilegen können, ein Standpunkt, dem sich noch neuerdings Flitner ${ }^{1}$ ) in seiner Arbeit uber die vorliegende Frage angeschlossen hat. Dass ein solcher Zusammenhang zwischen Verletzungen einerseits und Neubildungen andererseits thatsächlich existirt, dafür sei auf die beweisenden Fälle der genannten Arbeit, sowie auf den Aufsatz von Pfingst") (Melanosarkom der Corneoskleralgrenze und Sarkome der Thränendrüse nach Traumen) neben vielen anderen $\mathrm{Ab}$ handlungen $\mathrm{zu}$ diesem Thema verwiesen.

Von der Ueberzeugung ausgehend, dass man nicht berechtigt sei, alle diese die Körperoberfläche betreffenden Erfahrungen ohne Weiteres auf die im Bulbusinnern in geschützter Lage befindliche Chorioidea zu übertragen, haben Leber und Krahnstöver ${ }^{3}$ ) neuerdings die Frage nach der ätiologischen Bedeutung der Verletzungen für die Aderhautsarkome in Angriff genommen und die in der Literatur beschriebenen 34 Fälle $^{4}$ ) angeblich traumatischen Ursprungs einer sehr eingehenden Kritik unterzogen. Sie

1) F. Flitner, Ein Beitrag zur Lehre vom traumatischen Sarkom. Halle 1896.

₹) y. Zehender's Monatsblätter XXXIII. Bd. S. 252-263.

3) v. Graefe's Arch. f. Ophthalm. XLV. Bd. 1. Abth. S. 164 fr.

4) Davou stammen 30 von Fuchs, 4 von Lawson. 
scheideu von ihnen zunächst 6 Beobachtungen aus, bei denen es sich nicht mit Sicherheit um wirkliche Sarkome, sondern meist wohl nur um entzündliche Gewebsneubildungen handelte, und die zum Theil bereits Fuchs ${ }^{1}$ ) beanstandet hat. Ws bleiben somit von den 34 traumatischen Fällen der Literatur noch 28 übrig, gegen deren sarkomatöse Natur sich keine Einwendungen erheben lassen. Von diesen trennen Leber und Krahnstöver wiedermm eine Gruppe ron $12 \mathrm{ab}$, bei denen der Beginn der Sarkomentwickelung mit grosser Wahrscheinlichkeit bereits vor dem Einwirken des Traumas angenommen werden muss. Fon den $16 \mathrm{Be}-$ obachtungen, die restiren, machen sie noch einen Abzug von 7 Fällen, in denen das Trauma ohne direkte nachweisbare Folgen geblieben war. Hier fehlten also die entzündlichen und hyperplastischen Processe, wie sie Virchow ${ }^{2}$ ) und Fuchs ${ }^{3}$ ) als Bindeglied zwischen der Verletzung einerseits und der Geschwulstentwickelung andererseits aufgestellt haben. Leber und Krahnstöver sind daher geneigt, anzunehmen, dass hier das Trauma vielleicht nur in Ermangelung sonstiger ätiologischer Momente therhaupt herangezogen worden ist. So bleiben nur noch 9 Fälle, in denen ein Trauma zu pathologisohen Verändernugen oder gar zum Untergang des Auges geführt und später ein Aderhautsarkom in demselben sich entwickelt hatte. Die Verletzung bestand entweder in einer mit grösserer Gewalt einwirkenden Contusion oder in perforirenden Trammen. Aber auch von diesen Fällen lassen die genannten Forscher 5 nicht als beweiskräftig gelten, weil ihnen dor Zeitraum zwischen der stattgehabten Verletzung und dem Auftreten des intraocularen Tumors zu gross erscheint, um einen ursächlichen Zusammenhang zwischen beiden wahrscheinlich zu machen. Die angegebenen $Z$ wischenzeiten, in denen das verletzte A uge ohnejede

x) Loc. cit S. 157 und 235 .

2) Loc. cit. II. Bd. S. 249.

s) Loc. cit. 8.236. 
weitere Veränderung geblieben sein soll, betragen in drei Fällen mehr als ein Jahrzehnt, darunter einmal 17, ein andermal sogar 25 Jahre. Der kürzeste Zeitraum zwischen Verletzung und Entwickelung des Sarkoms war in dieser Gruppe 8 Jahre. Mit ihrer Anschauung setzen sich die Autoren in Gegensatz zu Fuchs, der mit Boyer und Roux für einen Fall von Chorioidealsarkom noch eine ror 40 Jahren erfolgte schwere Verletzung des Auges verantwortlich macht, während Virchow (l. c. II. Bd. S. 249) seinerseits hierbei Zweifel bezüglich des causalen Zusammenhangs äussert. Die Anzahl der wirklich stichhaltigen Fälle ist damit auf 4 zusammengeschmolzen, in denen einerseits die Verletzung eine eingreifende war, andererseits die zeitliche Aufeinanderfolge eine gewisse Beziehung zwischen der Tumorentwickelung und dem voraufgehenden Trauma wahrscheinlich macht. Bei der Kleinheit dieser Zahl gegenüber der Menge der bekannten Fälle von Uvealsarkom und gegenüber der Häufigkeit gleicher Verletzungen ohne nach. folgende Sarkomerkrankung wird man auch hier in dem Trauma höchstens eine Veranlassung zur Geschwulstbildung, nicht aber ihre eigentliche Ursache erblicken.

Gehen wir schliesslich daran, die Methode von Leber und Krahnstöver auf unsere Fälle anzuwenden, so finden wir unter diesen überhaupt nur $10^{1}$ ), bei denen die Anamnese irgend welche positiven ätiologischen Angaben enthält. Davon fallen 2 von vornherein aus dem Rahmen der Erörterung heraus, in denen einmal (Fall 49) ein Carbunkel des Orbitalrandes seit 11 Jahren eine Abnahme des Sehvermögens bis zu völliger Amaurose und schliesslich die Entstehung eines Chorioidealsarkoms herbeigeführt haben soll, ein andermal (Fall 65) in dem seit Kindheit amblyopischen Auge eines 26 jährigen Mannes ein Sarkom zur Beobachtung gelangte. Das angegebene Alter schliesst in dem

1) Fall 2, 36, 37, 49, 53, 65, 77, 83, 87, 92 . 
E. Pawel.

letzteren Falle den Gedanken, dass etwa der Tumor schon die Veranlassung der bestehenden Amblyopie gewesen sein könnte, ebenso aus, wie den, dieser Amblyopie eine causale Bedeutung für die Geschwulstentwickelung zuzuschreiben. Zum Ueberfluss lässt auch die Anamnese (seit 6 Monaten Amaurose, seit einigen Wochen Schmerzen) einen erst seit Kurzem zu datirenden Beginn derselben mit grösster Wahrscheinlichkeit annehmen. In den übrig bleibenden 8 Fällen war siebenmal ein Trauma als Ursache des später entdeckten Sarkoms angeschuldigt worden; dabei handelte es sich zweimal um eine Contusion "), viermal um eine perforirende Verletzung durch Eisensplitter ${ }^{2}$ ), Hufschlag ${ }^{3}$ ) und Strohhalmstoss ${ }^{4}$ ) und einmal um eine ausgedehnte Hautverbrennung, aber ohne Läsion des Bulbus ${ }^{5}$ ). Im achten Fall ${ }^{6}$ ) bestand der Tumor bereits vor dem Trauma, durch welches ex nur zu schnellerem Wachsthum angeregt wurde.

Was die erstgenannte Gruppe anlangt, so ist für den Fall 83 ein Causalnexus zwischen Trauma und Neubildung allerdings stark anzuzweifeln. Der ror 6 Jahren erlittene Schlag auf das Auge scheint nur zu einer vorübergehenden Schwellung dor umgebenden Weichtheile geführt zu haben, wie sie ja an den Lidern oft schon nach leichten Contusionen in beträchtlicher Ausdehnung zu beobachten ist. Von einer nachweisbaren Schädigung des Bulbus selbst oder einer Störung des Sehvermögens verlantet nichts, und auch die geschilderte Schwellung der Umgebung ging bald zurück. Während der nächsten $33_{2}^{1}$ Jahre war das Auge völlig gesund. Folgen des Traumas waren also in keiner Weise zuriickgeblieben. Erst nach diesem Zeitraum $(2 \% / 2 \mathrm{~J}$.

\footnotetext{
1) Fall 83 u. 87 .

2) Fall 36 .

3) Fall 37 .

4) Fall 53 a. 77.

5) Fall 92.

5) Fall 2.
} 
vor der Operation) stellte sich unter Entzündungserscheinungen und Schmerzen eine Abnahme des Sehvermögens ein, als deren Ursache ärztlicherseits eine Netzhautablösung erkannt wurde. Es ist ausser allem Zweifel, dass diese bereits als erstes Symptom des sich entwickelnden Tumors zu deuten ist, und da dessen Sitz, wie die spätere anatomische Untersuchung ergab, gerade die Gegend des hinteren Poles war, also schon frühzeitig das centrale Sehen in Mitleidenschaft gezogen werden musste, wird man nicht fehlgehen, den Beginn der Neubildung nicht allzuweit vor der Entdeckung der Sehstörung zu datiren. Somit lässt sich zwischen der Contusion und dem ersten Beginn des Sarkoms eine völlig normale Zwischenzeit von etwa 3 Jahren constatiren, eine Thatsache, die einen Zusammenhang zwischen beiden Vorgängen zum mindesten unwahrscheinlich macht.

Sehr viel näher liegt eine solche Verknüpfung in dem zweiten Falle (87 der Tabelle). Hier trat im Anschluss an einen Stoss vor das bis dahin gesunde Auge eine Gesichtsfeldbeschränkung nach oben auf, der im ophthalmoskopischen Bilde eine hämorrhagische Ablösung der unteren Netzhauthälfte entsprach. Noch im Verlauf eines Jahres kam es zu glaukomatösen Anfällen und Amaurose und der Fall begann verdächtig zu werden, als sich in den folgenden 3 Jahren allmählich unter Schmerzanfällen subconjunctivale Vorbuckelungen der Sklera ausbildeten. Die Enucleation des Auges ergab denn auch ein Aderhautsarkom, das bereits einige kleine episklerale Knötchen geliefert hatte. In der That vermag der ganze Verlauf dieser Beobachtung den Anschein zu erwecken, als ob hier das Trauma, und nur dieses allein, die Ursache der Geschwulstbildung gewesen sei; nach den Ausführungen von Leber und Krahnstöver können wir in ihm jedoch höchstens eine Gelegenheitsursache, einen Anstoss zur Entstehung der Neubildung sehen, und für diese Deutung giebt uns ein Vergleich mit dem letzten der ci- 
E. Pawel.

tirten Fälle (2 der Tabelle) eine recht brauchbare Illustration. Derselbe betrifft ein Sarkom, welches sich aus einem kleinen Pigmentfleck der Iris entwickelt hatte; derselbe wurde $51_{2}$ Jahre vor der Operation zufällig entdeckt, bestand aber, wie die Patientin zugiebt, wahrscheinlich schon längere Zeit vorher. Sein Wachsthum war ein äusserst geringfügiges, Beschwerden oder Sehstörung verursachte es 4\% Jahre lang in keiner Weise. Dieses Bild änderte sich mit einem Schlage, als Patientin nach Ablauf dieser Zeit einst beim Bücken über einen Kessel mit siedendem Wasser unvermuthet ron heissen Dämpfen getroffen wurde, worauf sofort eine Blutung in die Vorderkammer erfolgte. Die unmittelbare zeitliche Aufeinanderfolge dieser beiden Ereignisse lässt an ihrem causalen Zusammenhang keinen $Z$ weifel aufkommen. Von diesem Tage an begann ein schnelleres Wachsthum der Geschwulst, es traten Schmerzen und Drucksteigerung hinzu, und das anfangs durch den Bluterguss völlig aufgehobene Sehvermögen stellte sich auch nach dessen Resorption nicht mehr im alten Masasstabe wieder her. Auch hier finden wir also, ganz analog dem Falle 87, einen intraocularen Bluterguss als Folge des Traumas, dem sich innerhalb des nächsten Jahres zunehmende Sehstörung und glaukomatöse Erscheinungen ansehliessen; auch hier wirde sicherlich dieses Trauma zur Ursache des vorhandenen Tumors gestempelt worden sein, wenn nicht sein Sitz in der Iris im Gegensatz zu den chorioidealen Sarkomen bereits vorher die Entdeckung seiner ersten Entstehung im frühesten Stadium ermöglicht hätte.

Eine gewisse änsserliche Beziehung zu dieser Beobachtung besitzt hinsichtlich des in Frage kommenden Traumas der Fall 92, bei welchem eine ausgedehnte Hautverbrennung mit kochendem Wasser 14 Jahre vor der Entfernung des sarkomatös erkrankten Auges stattgefunden hatte. Nach seiner Genesung entdeckte der Patient plötzlich eine Erblindung seines linken Auges und fthrt die- 
selbe auf das erlittene Trauma zurick, obwohl dieses zwar die Cmgebung des Auges, nicht aber den Bulbus selbst getroffen hatte. Als Ursache der Erblindung fand sich eine weit vorgedrängte Netzhautablösung, äusserlich bot das Auge nichts Abnormes.

Dass die Verletzung in diesem Falle eine schwere war, geht aus der langen Dauer der Bettlägerigkeit (o Monate) zur Genüge hervor, da aber der Bulbus dabei keine Läsion erfahren hatte, ist ein Zusammenhang zwischen ihr und der Erblindung, resp. der letzterer zu Grunde liegenden Netzhautablösung nicht recht zu erklären. Trotzdem das Auge nun fast 14. Jahre obne Veränderungen blieb, und erst nach dieser Zeit ein rasch wachsendes Sarkom beobachtet wurde, muss man die Netzhautabhebung mit Wahrscheinlichkeit als Folge eines sich entwickelnden Tumors auffassen. Das zeitliche Zusammentreffen der Ablösung und des Traumas, das vielleicht nur ein scheinbares ist, indem die einseitige Prblindung möglicher Weise schon vorher bestand und dem Patienten erst in dieser Zeit zum Bewusstsein kam, wird man nicht anders als ein zufälliges deuten können; ein Causalnexus zwischen beiden, resp. zwischen Trauma und Sarkom, ist schwerlich aufrecht zu. erhalten.

Das Gleiche gilt von dem Fall 37 der zweiten Gruppe, bei welchem 8 Wochen nach einer Verletzung durch Hufschlag auf das Auge ein Aderhautsarkom im zweiten Stadium zur Beobachtung kam. Das Trauma hatte in kürzester Frist zu Amaurose und Phthisis bulbi geführt; dass aber in der angegebenen Zeit ein Chorioidealsarkom als Folgezustand entstanden und sogar bereits in das zweite Stadium eingetreten sein sollte, ist nach allem, was wir von der ersten Entwickelung und der Dauer des Anfangsstadiums der Uvealsarkome wissen, zum mindesten sehr unwahrscheinlich. Viel eher wäre es denkbar, dass die Verletzung auch hier wieder nur den Anstoss zu schnellerem 
Wachsthum einer bis dahin unbemerkt gebliebenen Geschwulstanlage gegeben hat, doch lassen sich für eine sichere Beurtheilung des Falles weder aus der Anamnese, noch aus dem Status hinreichende Anhaltspunkte erbringen. Da eine Operation und anatomische Untersuchung des Bulbus nicht stattgefunden hat, scheidet die Beobachtung übrigens an und für sich schon aus der Reihe der beweiskräftigen Fälle aus. Die letzten 3 Fälle $(36,53,77)$ haben das Gemeinsame, dass eine perforirende Verletzung entweder unmittelbar oder allmählich eine völlige Erblindung des betroffenen Auges zur Folge hatte, und nach einer Reihe von Jahren die Enucleation des sarkomhaltigen Bulbus vollzogen wurde. In der erstgenannten Beobachtung hatte das Trauma 7 Jahre vor der Operation sofort die Aufhebung des Sehvermögens herbeigefüht, doch fehlen genauere Angaben über den damals erhobenen Befund. Nachdem sich in den nächsten 4 Jahren keine weiteren Veränderungen gezeigt hatten, bemerkte der Patient von dieser Zeit an eine allmählich zunehmende Vergrösserung des verletaten Auges, als deren Ursache ein Aderhantsarkom vermuthet und bei der Section des enucleirten Auges auch gefunden wurde. Obwohl es in Folge der durch das jugendliche Alter des Patienten bedingten Nachgiebigkeit der Bulbushiillen erst kurze Zeit vor der Operation zu glaukomatösen Frscheinungen, also zum Eintritt des zweiten Stadiums gekommen war, muss der Beginn der intraocularen Neubildung dennoch mindestens 3 Jahre zurückdatirt werden, derselbe rückt also dem Zeitpunkt des Traumas höchstwahrscheinlich recht nahe. Noch ansgeprägter ist dieses zeitliche Verhalten in den beiden folgenden Beobachtungen, in denen 3 resp. 4 Jahr vor der Enucleation eine Strohhalmverletzung die Frblindung des Auges herbeigeführt hatte.

Während sich dieselbe im. Fall 53 unter dem Bilde einer schleichenden Iridochorioiditis langsam vollzog, stellte sich in dem anderen Falle ( 77 der Tabelle) rasch eine 
Panophthalmie mit Phthisis dolorosa ein; in beiden Fällen enthielt der im zweiten Stadium enucleirte Bulbus ein Aderhautsarkom. In allen diesen drei Beobachtungen, namentlich in der letzten ist ein Zusammenhang des Traumas mit der Sarkomerkrankung sehr gut denkbar, nur sehen wir in ihm nach der aus Fall 2 gezogenen Lehre nicht die eigentliche zu Grunde liegende Ursache der Neubildung, sondern nur einen Anstoss, ein veranlassendes Moment zu ihrer Entwicklung.

\section{Verlauf.}

Der klinische Verlauf der Sarkomerkrankung der Uvea ist bereits von $\mathrm{Knapp}^{2}$ ) in vier Stadien zerlegt worden, und diese Eintheilung hat sich in prognostischer Hinsicht als zweckmässig bewährt. Sie liegt daher auch unserer obigen Tabelle zu Grunde. Da die bekannten Erscheinungen des Uvealsarkoms einer Darstellung nicht mehr bedürfen, sei es gestattet, hier nur einige Abweichungen vom gewöhnlichen Veriaufe kurz zu erwähnen.

In seltenen Fällen verläuft das zweite Stadium der Chorioidealsarkome unter dem Bilde einer heftigen, plastischen Iridocyclitis, die zuweilen schliesslich zu einer vollkommenen Atrophie des Bulbus führt. Als Ursache einer solchen Phthisis bei Aderhautsarkom nahm v. Graefe eine vorangehende Zerstörung der Cornea an, der eine Panophthalmie folgen sollte. Die Erfahrung hat aber gelehrt, dass dies nur selten der Fall ist, und die Atrophie vielmehr durch eine Schrumpfung der iridocyclitischen Exsudate im Augeninnern herbeigefuhrt wird.

Die Phthisis bulbi nach Aderhautsarkom ist in neverer Zeit der Gegenstand eingehender Forschungen vonseiten verschiedener Autoren gewesen. Evetzky²) und

i) Loc. cit. S. $178 \mathrm{pr}$.

2) Ewetzky, Ueber Sarkome in atrophischen Augen. Aperçu de l'activité du cercle ophthalm. de Moscou. Séance du 7. Oct. 1896, 
Th. Leber $\left.{ }^{1}\right)$ haben ungefähr gleichzeitig und unabhängig von einander durch anatomische Untersuchungen nachgewiesen, dass diese Fälle ron Sarkom, welche zu Entziindungen des Uvealtractus und zu Atrophie des Auges geführt hatten, sich durch eine ausserordentliche Verbreitung degenerativer und nekrotischer Processe auszeichnen, wie sie bei den gewöhnlichen, mit Drucksteigerung einhergehenden Fällen sich nicht in dieser Weise findet ${ }^{2}$ ). Ewetzky ist der Meinung, dass diese Entzïndungen durch die Stoffwechselproducte der in Zerfall gerathenden Massen hervorgerufen würden, und führt diesen Zerfall selbst wieder auf eine mangelnde Ernährung (z. B. in Folge ron Endarteriitis) zurück. Leber and Krahnstöver sind dagegen geneigt, die Entzindung auf eine Infection zuxückzuführen und die Bedeutung der Nelzrose mehr darin zu suchen, dass sie günstige Bedingungen für die Ansiedelung ron pathogenen Mikroorganismen setzt, ohne sich aber in dieser Beziehung mit voller Bestimmtheit auszusprechen.

In naher Beziehung zu diesen unter dem Bilde einer Tridocychitis verlaufenden Fällen steht die Frage nach dem

im Druck erschienen zum 15. Ang. 1897. Die ausführlichere Arbeit erschien erst am 17. Juni 1898: „Weitere Studien über intraoculare Sarkome. II. Sarkome in atrophigchen Augen." v. Graefe's Arch. f. Ophthalin. XLV. Bd., 3. Abth. S. 563 ff. (1898).

1) Th. Leber, Ueber die Combination von intraoularen Geschwülsten mit Phthisis bubi. Sitzungsber. d. ophthalm. Ges. Sitz. ¥. 7. Ang. 1897, im Druck erschienen 1898.

Th. Leber und A. Krahnstöyer, Veber die bei Aderhantsakkomen vorkommende Phthisis des Augapfels u. über die Bedentung yon Verletzungen bei der Entstehung dieser Geschwilste (Schluss). v. Graefe's Arch. f, Ophthalm. XLV. Bd. 2. Abth. Ausgegeben atn 3. Mai 1898 .

₹) In der Nehrzahl der Falle handelte es sich um Bulbi, die sich bereits in atrophischem Zustande beranden, doch liegen auch Befunde ron fruheren Stadien rox, in denen es noch nicht, so weit gekommen war oder der Cebergang in Atrophie sich zunächst nur durch Herabsetzung des intraocularen Druckes ankündigte. 
Zusammenhang von sympathischer Ophthalmie und Aderhautsarkom. Schirmer ${ }^{1}$ ) hat dargethan, dass ein $\mathrm{Zu}-$ sammentreffen beider Affectionen als ein recht seltenes Ereigniss betrachtet werden muss und nur in den Fällen zu erwarten ist, wo sich das Sarkom im sympathisirenden Auge mit einer Entziindung der Uvea complicirte. Der Weg, auf dem diese Complication erfolgte, ist in allen denjenigen Beobachtungen unzweifelhaft, bei welchen es zu einer Eröffnung der Bulbuskapsel entweder durch operative Eingriffe oder durch spontane Perforation des Tumors gekommen war; hier handelte es sich mit grösster Wahrscheinlichkeit um eine ektogene Infection mit den bisher unbekannten Erregern der sympathischen Ophthalmie. Unter 14 Fällen von letzterer bei Aderhautsarkom, welche Leber und Krahnstöver zusammengestellt haben, fand sich ein solches Verhalten achtmal ${ }^{2}$ ); der angegebene Weg ist also unstreitig der häufigere. Schwieriger ist die Frage in den Fällen, in welchen eine nachweisliche Eröffnung des Bulbusinnern nicht stattgefunden hat; wir haben bereits erwähnt, dass Ewetzky die Stoffwechselproducte der in derartigen Sarkomen sich findenden Degenerationsheerde als die Ursache der Iridocyclitis ansieht, während Leber, von der parasitären Theorie der sympathischen Entzündung ausgehend, für diese Fälle eine vermuthlich endogene Infection voraussetzen muss, für deren Entstehung die Degeneration des Tumors die Wege ebnete. Möglich wäre in diesen Fällen aber auch, dass kleine, der Wahrnehmung entgangene Continuitätstrennungen der Gewebe zur Einwanderung der pathogenen Organismen von aussen her Gelegenheit gegeben hätten. Ein Analogon bietet sich z. B. in dem Verhalten der subconjunktivalen Bulbusrup-

1) O. Sch irmer, Klinische und pathologisch-anatomische Untersuchungen zur Pathogenese der sympathischen Augenentzündung. y. Graefe's Arch. f. Ophthalm. XXXVIIL. Bd. 4. Abth.

2) Loc. cit. S. $26 \%$.

₹. Graefe's Archiv fur Ophthalmologie. XuIX, 1. 
turen, nach denen zuweilen sympathische Ophthalmie zur Beobachtung kam. Dass die ausgedehnten nekrotischen Processe, wie sie für die obige Gruppe von Sarkomen beschrieben worden sind, immerhin bei der Ansiedelung der Krankheitserreger eine bedeutende Rolle spielen, ergiebt sich aus der relativen Häufgkeit, mit der gerade diese Fälle zu sympathischer Entzündung des zweiten Auges gefuhrt haben. Leber und Krahnstöver fanden eine solche siebenmal unter 44 mit Phthisis bezw. Hypotonie einhergegangenen Beobachtungen ron Chorioidealsarkom, $=16 \%$ der Fälle, während sie bei den typisch verlaufenen Sarkomfällen ebenfalls nur siebenmal, also in einem ganz verschwindenden Bruchtheil auftrat und auch hier ausnahmslos nach vorangegangener spontaner oder operativer Fröfmung der Bulbuskapsel.

Unter unseren Fällen wurde sympathische Ophthalmie nur einmal angetroffen (Fall 76 der Tabelle). Es handelte sich um eine 43jährige Frau, die unter den Erscheinungen des entzündlichen Glaukoms in die Klinik kam und bei der eine diffuse Trübung der brechenden Medien die ophthalmoskopische Untersuchung des Augenhintergrundes unmöglich machte. Es wurde iridektomirt, und als keine Besserung eintrat, 6 Wochen später die Enucleation des schmexzhaft-amaurotischen Auges vollzogen. Nach einer Woche, also 7 Wochen nach der Iridektomie, brach auf dem zweiten Auge eine heftige plastische Iridocyclitis aus, die trotz aller therapeutischer Anstrengungen einen malignen Ausgang nahm: es kam zu Erblindung und vollständiger Atrophie. Der zeitliche Eintritt, sowie der ganze Verlauf und der Ausgang dieser Entzündung lassen über ihre Natur keine Zweifel zu. Die Beobachtung gehört in die erste der oben aufgestellten beiden Gruppen, da eine Eröffnung des sympathisirenden Auges voraufging.

Von den 4 Fällen unserer Tabelle, in denen Phthisis bulbi neben Sarkom bestand, ist in zweien (Fall 37 und 
77) die Phthise durch ein Trauma veranlasst worden, so dass diese beiden Beobachtungen hier bei der Besprechung ausscheiden. In den anderen beiden Fällen (80 und 84), welche sich durch eine sehr lange Verlaufsdauer auszeichnen, muss man die Atrophie als Folge eines primären Chorioidealsarkoms auffassen, da das letztere unzweifelhaft bereits vorher bestand, und eine anderweitige Ursache für sie nicht vorlag. Beide Male machte sich der Beginn der Tamorentwicklung durch eine plötzlich eintretende Netzhautabhebung mit Erblindung bemerkbar, ohne dass das Auge äusserlich in den nächsten Jahren irgend welche Abnormitäten gezeigt hätte. Erst nach dieser Zeit, im Fall 84 erst nach 10 Jahren, begann das Auge atrophisch zu werden; im Fall $80 \mathrm{kam}$ es weiterhin zu Partialektasie. der Sklera. Beide Fälle kamen erst im dritten Stadium, als die Neubildung bereits die Sklera perforirt hatte, zur Beobachtung; so dass über die Natur der Erkrankung kein Zweifel mehr obwalten konnte; in früheren Stadien kann indess die Diagnose eine überaus schwierige, ja völlig unmögliche sein.

Da der erste Beginn der Sarkomerkrankung in der überwiegenden Mehrzahl der Fälle nicht diagnosticirt und ferner bald nach der Entdeckung des Tumors die Enucleation ausgeführt wird, lässt sich über die eigentliche Dauer der Krankheit zumeist nichts Sicheres angeben. Tmmerhin ist jedoch eine ganze Reihe von Fällen bekannt, die über die zweifellos lange Gesammtdauer der Erkrankung eine genügende Aufklärung gewähren; Leber und Krahnstöver ${ }^{1}$ ) geben folgende Tabelle:

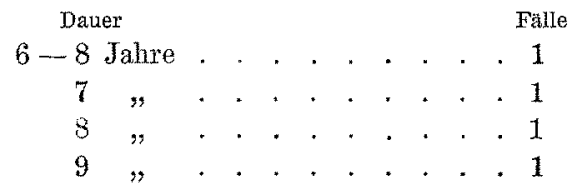

1) Loe. cit. \$. 185 . 


Daner
10 Jahre

Auch unter den von wair mitgetheilten Beobachtungen, vorzugsweise natürlich bei den im dritten Stadium der Krankheit operirten Patienten, finden sich ähnliche Zeitangaben, so

\begin{tabular}{|c|c|c|c|c|c|c|c|c|c|c|}
\hline 1 Fall & (78) & von. & & & & & & \multicolumn{3}{|c|}{ 6jähriger Daner } \\
\hline , & (85) & $"$ & & & & & . & 7 & \% & $\eta$ \\
\hline $1 \%$ & (99) & $\Rightarrow$ & . & . & & & . & 8 & 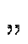 & , \\
\hline 2 Fälle & $(80$ น. 95$)$ & ". & & . & & & & 10 & , & $"$ \\
\hline 1 Fall & (93) & $"$ & & . & & & . & 11 & " & $"$ \\
\hline , & (92) & " . & . & : & & & . & 14 & $"$ & $n$ \\
\hline$n$ & (84) & $n$. & . & . & . & & & 17 & , & $"$ \\
\hline
\end{tabular}

In den meisten dieser Beobachtungen markirte sich der Beginn der Tumorentwicklung durch eine plötzlich auftretende Netzhautabhebung; in einem Fall (96), in dem 30 Jahre ror der Entfernung des sarkomhaltigen Bulbus im dritten Stadium sich Erblindung eingestellt haben soll, ohne dass über die Natur derselben nähere Angaben vorliegen, muss man wohl die Frage nach einem Zusammenhang derselben mit der Geschwulstbildung unentschieden lassen. Dass für die Irissarkome rerhältnissmässig häufig derartige lange Entwicklungszeiten berichtet werden, wird nicht Wunder nehmen, wenn man bedenkt, dass gerade bei ihnen schon der erste Anfang der Neubildung zur Beobachtung kommen kann; in unsern beiden Fällen sind die angegebenen Zeiten indes relativ klein, obwohl sie erst im zweiten resp. dritten Stadium zur Operation gelangten.

Schwieriger zu berechnen ist die Dauer der einzelnen Stadien, speciell des ersten. Hierzu ist einmal die Bestim-

1) E. v. Hippel, Loc. cit. 
mung des ersten Beginns der Erkrankung erforderlich, und zweitens auch die des Anfangs des zweiten Stadiums; dio Patienten müssen also später als im ersten Stadium operirt worden sein. Aus 24 geeigneten Fällen der Tabelle ergiebt sich als Dauer des ersten Stadiums ein Zeitraum von 2 Jahren und drei Monaten, während Fuchs 21 Monate gefunden hat. Sicherlich sind alle diese Zahlen zu niedrig, da der Beginn der Geschwulstentwickelung wohl in der Regel weiter zurück liegt, als die Angaben besagen. Damit stimmt die Thatsache überein, dass sich unter unseren 24 Beobachtungen nicht weniger als sechs mit längerer Dauer vorfinden, närnlich:

$1(48)$ mit 3 jähriger

" $\quad 6$

$2(84 u, 95) ; 10$ " Dauer des ersten Stadiums.

Für das zweite Stadium ergiebt sich ein Zeitraum von 2 Jahren und 1 Monat (aus 4 Fällen berechnet); Fuchs giebt ebenfalls 21 Monate an und erwähnt bereits, dass das zweite Stadium mitunter völlig übersprungen wird, indem es im Anschluss an das erste rejzfreie Stadium schon zu episkleralen Knoten kommt ${ }^{1}$ ). Für das dritte und vierte Stadium lassen sich keine bestinamten Zeitangaben machen.

\section{Prognose.}

I.

Da das Sarkom des Uvealtractus einer spontanen Heilung wicht fähig ist, vielmehr in jedem nicht durch Operation behandelten Falle unbedingt zum Tode führt, muss die Prognose als absolut infaust bezeichnet werden. Unter den mitgetheilten Beobachtungen befindet sich eine,

1) cf. Fall 89 und 94 . 
in welcher der Patient die Operation ablehnte (Fall 37 der Tabelle): derselbe starb nach drei Jahren an einer mehrmonatlichen Lungenentzündung (Lungenmetastasen?), ohne dass genauere Angaben iuber die Todesursache und das weitere Verhalten des sarkomatösen Auges in Erfahrung zu bringen waren. Nimmt man an, dass das als Ursache angeschuldigte Trauma wirklich den Beginn der Tumorentwicklung darstellt, so hätte der Gesammtverlauf wenig uber 3 Jahre gedauert; wahrscheinlich ist dieser Zeitraum jedoch zu niedrig gegriffen. In drei Beobachtungen nicht operirter Patienten, welche von Beginn an bis zum Tode verfolgt werden konnten, hat Fuchs die Gesammtdauer der Krankheit $z \mathfrak{u} 5^{1 / 2}, 3^{3 / 4}$ und $1 / 2$. Jahren gefunden. (l. c. p. 272.)

II.

Die operirten Fälle von Irissarkomen geben eine relativ günstige Prognose, da sie in der Regel früh zur Diagnose und zur Operation kommen. Nach Fuchs blieben von acht längere Zeit beobachteten Fällen sieben frei von Recidiven; davon drei, in denen die Geschwulst durch Tridektomie entfernt worden war. Metastasen sind noch nicht constatiut worden. Von den beiden Irissarkomen unserer Tabelle wurde das erste im dritten Stadium durch Fnucleatio bulbi entfernt; die Patientin ist nach 16 Jalren noch gesund. Im zweiten Falle kam nur die Tridektomie in Anwendung, und auch diese Patientin kann nummehr nach Ablauf von 7 Jahren als definitiv geheilt angesehen werden.

\section{III.}

Sarkome der Chorioidea und des Ciliarkörpers.

Von den 98 hierher gehörigen Fällen müssen $8^{1}$ ) wegen Mangels weiterer Angaben über die Schicksale des Patienten,

1) $11,29,33,44,48,64,69,96$ 
sowic $1^{1}$ ) bei welchem keine Operation stattfand, von vornherein ausgeschieden werden.

Unter den 89 verbleibenden Fällen stellte sich neunmal, also in 10 Proc, ein locales Recidiv ein.

Bezüglich der Zeit, in welcher das geschah, giebt folgende Zusammenstellung Aufschluss:

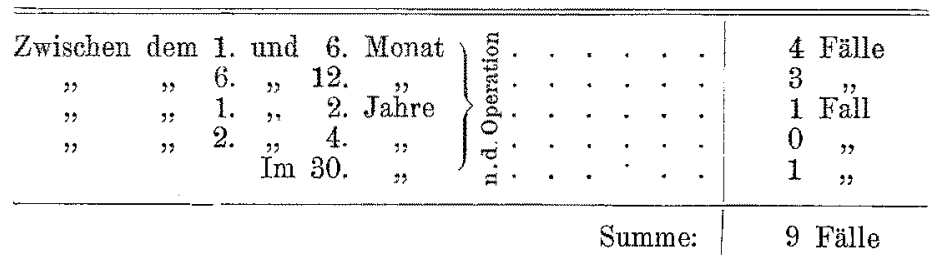

In den ersten sechs Monaten nach der Operation ist also die Gefahr des localen Recidivs am grössten und fällt mit der Zunahme des recidivfreien Zeitraums nach ihr, Ausnahmsweise tritt es aber auch wesentlich später auf. So berichtet Fuchs über Recidive nach 7, resp. 9 Jahren, Wecker von einem Fall, in dem nach 9 Jahren das erste Recidiv, nach 16 Jahren ein zweites auftrat. Freudenthal, der eine ungewöhnlich hohe $Z$ ahl von Recidiven anfuhrt (6 unter $24=25$ Proc.), sah ein solches noch nach 10 Jahren, am merkwürdigsten erscheint jedoch der Fall 19 unserer Tabelle, bei welchem im 30. Jahre nach der Fnucleatio bulbi wegen Chorioidealsarkoms ein Melanosarkom der Orbita, das vom Enucleationsstumpf ausging, zur Beobachtung kam. Diese Fälle beweisen, dass selbst noch nach Jahrzehnten scheinbarer Heilung die Gefahr der Recidive vorhanden sein kann; bei ihrer grossen Seltenheit können sie aber die Prognose nicht wesentlich beeinträchtigen. Im Allgemeinen kann man einen Patienten, der 4. Jahre hindurch recidivfrei geblieben ist, mit grösster Wahrscheinlichkeit als geheilt betrachten; in unsern Fällen traten acht von den beobachteten neun Recidiven bereits innerhalb der ersten 2 Jahre auf.

1) S. 37 . 
Von grösster Bedeutung für das Vorkommen von Recidiven ist das Stadium, in welchem die Operation stattfand, wie aus nachstehender Tabelle hervorgeht:

\begin{tabular}{c|c|c|c}
\hline \hline Stadium & $\begin{array}{c}\text { Gesammatzahl } \\
\text { der Falle }\end{array}$ & $\begin{array}{c}\text { Zahl } \\
\text { der Recidive }\end{array}$ & Procentsatz \\
\hline I. & 15 & 0 & 0 \\
II. & 52 & 2 & 4 \\
III. & 22 & 7 & 32 \\
\hline Summe: & 89 & 9 & 10
\end{tabular}

Zu ähnlichen Resultaten gelangt auch Fuchs (1. c. p. 275).

Ist einmal ein Recidiv aufgetreten, so ist von der Operation desselben in der Regel keine dauernde Heilung mehr zu erwarten. Von unseren neun Recidiven wurde in vier Fällen eine Exenteratio orbitae ausgeführt, zwei der Patienten starben bald darauf an Hirnsarkom, ein dritter an Generalisation des Tumors; über den vierten waren weitere Nachrichten nicht erhältlich.

Weit häufiger als die lokalen Recidive sind Metastasen der Geschwulst in entfernten Organen. Unter den 89 Fällen, in welchen Nachrichten über das spätere Ergehen der Patienten vorliegen, wurde $27 \mathrm{mal}=30$ Proc. das Auftreten von Metastasen beobachtet.

Dasselbe futhrte zum Tode in 26 Fällen, und zwar:

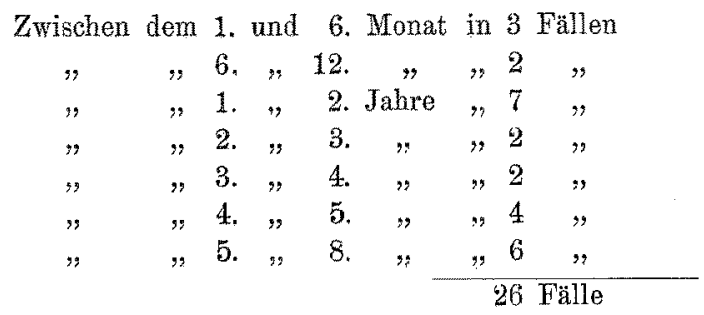

In der Mehrzahl der Fälle erfolgte also innerhalb der ersten fünf Jahre der Tod, eine Heilung der Metastasen 
galt bis in die neueste Zeit hinein für unmöglich. Die moderne Chirurgie hat nun auch hier den Versuch unternommen, diesen Metastasen operativ entgegen zu treten, und, wie es bisher scheint, in einzelnen Fällen nicht ohne Erfolg. Ein Beispiel ist der Fall 17 unserer Tabelle, in welchem sechs Jahre nach der Enucleation des sarkomhaltigen Auges ein circumskripter Tumor der Leber sich ausgebildet hatte. Es kam zur Exstirpation desselben, wobei er sich als ein metastatisches Lebermelanosarkom erwies; die Heilung verlief gut, und die Patientin ist jetzt $3 / 4 \mathrm{Jahr}$ nach dieser Operation, noch am Leben und bei zufriedenstellender Gesundheit.

In zwei Beobachtungen, in welchen eine Reihe von Jahren nach der Operation der Tod in Folge von Erkrankung an malignen Tumoren eintrat, handelte es sich wahrscheinlicher Weise nicht um eine Metastasirung des Aderhautsarkoms, sondern um primäre, von letzterem unabhängige Neubildungen. Der eine Fall ( 6 der Tabelle) betrifft eine Patientin, die 12 Jahre nach der Enucleation an einem. Uterustumor erkrankte und trotz ausgeführter Totalexstirpation starb. Die klinische Diagnose war auf Carcinoma uteri gestellt worden, eine histologische Untersuchung des Präparates hat nicht stattgefunden. $\mathrm{Da}$ es sich bei dieser Beobachtung um ein ungefärbtes Sarkom bei einer relativ jugendlichen, noch nicht im Carcinomalter stehenden Patientin handelte, wäre der Gedanke an Metastasenbildung nicht von der Hand zu weisen, wenn nicht die lange Dauer der völlig normalen $Z$ wischenzeit - 12. Jahre - denselben doch recht unwahrscheinlich erscheinen liesse.

Aehnlich verhält es sich mit dem zweiten Fall (50 der Tabelle). Hier stellte sich 10 Jahre nach der Operation ein Magenleiden ein, als dessen Ursache ein Carcinoma ventriculi diagnosticirt wurde. Die Patientin starb noch im Verlauf des Jahres, eine anatomische Diagnose liegt nicht vor. 
Bezüglich der Häufigkeit der Metastasen je nach dem Stadium, in welchem die Operation ausgeführt wurde, ergiebt sich folgende Tabelle:

\begin{tabular}{c|c|c|c}
\hline Stadium & $\begin{array}{c}\text { Gesammtzahl } \\
\text { der Fälle }\end{array}$ & $\begin{array}{c}\text { Zahl } \\
\text { der Metastasen }\end{array}$ & Procentsatz \\
\hline I. & 15 & 8 & 53 \\
II. & 52 & 12 & 23 \\
III. & 22 & 7 & 82
\end{tabular}

Ueberraschender Weise findet sich also der höchste Procentsatz der Metastasen für die mitgetheilten Fälle gerade bei den frühzeitig, noch im ersten Stadium ausgeführten Operationen, ein Beweis, dass im Gegensatz zu dem Verhalten der Recidive, selbst eine frühzeitige Operation nicht im Stande ist, Metastasen mit Sicherheit zu verhindern. Sobald Geschwulstzellen in den Kreislauf gerathen sind, kömnen sie eben zu Metastasen Veranlassung geben, ohne Beziehung zu der Grösse oder dem Entwicklungsstadium der Muttergeschwulst.

Von Recidiven und Metastasen wurden unter unsern 89 Fällen insgesammt 35 Patienten befallen = 39 Proc., während die übrigen $54=61$ Proc. von beiden verschont blieben. Dieses Verhältniss ist jedoch unstreitig zu günstig; da auch die Fälle jüngeren Datums bei der Berechnung Verwendung fanden. Schaltet man diese letzteren aus und verwerthet nur diejenigen, in welchen die Beobachtungszeit mehr als 5 Jahre beträgt, so erhält man auf 69 Fälle $34 \mathrm{mal}$ ein Auftreten von Metastasen und Recidiven $=49$ Proc. Todesfälle, die definitiven Heilungen belaufen sich somit auf 51 Proc. Die Prognose ist daher nach den hentigen Erfahrungen durchaus nicht so unginstig zu stellen, als es in friheren Zeiten, wo man in der Regel erst spät diagnosticirte und operirte, geschehen ist.

Am Schlusse dieser Arbeit ist es mir eine frendige Pflicht, Herrn Geheimrath v. Hippel für die gütige Ueberweisung des Themas und das jederzeit gewährte wohl- 
wollende Interesse meinen ehrerbietigsten Dank auszusprechen.

Herrn Dr. Schieck, Assistenzarzt der Klinik, bin ich für manche liebenswürdige Anleitung zu verbindlichem Danke verpflichtet.

\section{Literaturverzeichniss.}

1) Alt, Klinischer Bericht über die Knapp'sche Augenheilanstalt. Knapp's Arch. f. Augen- u. Ohrenheilk. VII. S. 395 ff.

2) Bäumler E., Ein Fall von Orbital - und Uvealsarkom. Klinische Monatsblatter f. Augenheill. 1886. S. 5 ff.

3) Brière Leon, Etude climique et anatomique sur le Sarcôme de la choroide et sur la mélanose intraoculaire. Thèse de Paris 1873.

4) Cohn H., Rückblicke. Breslau 1897.

5) Cohnheim, Vorlesungen über allgemeine Pathologie Berlin 1877. I. Bd. S.

6) Ewetzky, Weitere Studien über intraoculare Sarkome, II, III und IV; v. Graefe's Arch. f. Ophthalm. XLV. Bd. 3. Abth. S. $563 \mathrm{ff}$.

7) Flitner F., Gin Beitrag zur Lehre vom traumatischen Sarkom. Inaug.-Diss. Halle 1896.

8) Freudenthal, v. Graefe's Arch. f. Ophthalm. XXXVI. Bd. 1. Abth. 18.1.

9) Fuchs E., Das Sarkom des Uvealtractus. Wien 1882.

10) A. v. Graefe, Sein Arch. f. Ophthalm. XIV. Bd. 2. Abth. S. $101 \mathrm{ff}$.

11) Groenou A., Zwei Falle von Aderhantlösung (scheinbarem Chorioidealtumor) nach Cataractoperation mit spontaner Heilung. Arch. f. Augenheilk. XX. Bd. S. 69.

12) Heldmann B., Ein Fall von Cysticercus subretinalis unter dem Bilde eines intraocularen Tumors. Inaug.-Diss. Halle 1896.

13) E. v. Hippel, Ueber recidivirende intraoculare Blutungen, bedingt durch einen Tumor. v. Graefe's Arch. f. Ophthalm. XL. Bd. 4. Abth. S. 266 ff.

14) Hirschberg, Zur sympathisehen Reizung und Entzündung. v. Graefe's Arch. f. Ophthalm. XXII. Bd. 4. Abth. S. 142.

15) Hirschberg. Knapp's Arch. f. Augen- und Ohrenheilkunde. X. S. 56 .

16) Hirschberg, Zur Prognose des Aderhautsarkoms. Virchow's Arch. XC., S. 1 ff. 1882.

17) Knapp H., Die intraocularen Geschwülste. Karlsruhe 1868.

18) Landsberg M., Zur Aetiologie und Prognose intra- and extraocularer Sarkome. Virchow's Arch. LXIII. S. $274 \mathrm{ff.}$

19) Leber a. Krahnstöver, Ueber die bei Aderhautsartrom vorkommende Phthisis des Augapfels und uber die Bedeutung von Verletzungen bei der Entstehung dieser Geschwülste. v. Graefe's Arch. f. Ophthalm. XLV. Bd. 1. Abth. S. $164 \mathrm{ff}$. 
124 E. Pawel, Beitrag zur Lehre von den Chorioidealsarkomen.

20) Martin W., Beiträge zur Prognostik der Uvealsarlkome. Inaug.Diss. Halle 1885 .

21) Mayer A., Beiträge zur Prognose des Aderhautsarkoms. Inang.Diss. Würzburg 1889.

22) Nieden, Ueber sympathisehe Entzündung in Folge von Sarkom der Chorioidea. Arch. f. Augenheilk. XXIX. S. 339-345.

23) Oemisch K., Ueber das Sarkom der Regenbogenhaut. Inaug,Diss. Halle 1892.

24) Pfingst, $Z$ wei interessante, durch Trauma entstandene Tumoren des Auges. r. Zehender's M. Bl. XXXIII, S. 252-263.

25) Saner H., Beitrag zur Casuistik der Irissarkome. Inaug-Diss. Halle 1883 .

26) Schieck F., Ueber die Ursprungsstätte und die Pigmentirung der Chorioidealsarkome. v. Graefe's Arch. f. Ophthalm. XLY. Bd. 2. Abth., B. 433 ff.

27) Schirmer 0., Klinische und pathologisch-anatomische Untersuchungen zur Pathogenese der sympathischen Angenentzündmg. v. Graefe's Arch. f. Ophthalm. XXXVIII. Bd. 4. Abth.

28) Virch ow K., Die lrrankhaften Geschwülste. II. Bd.

29) Wiegand A., Casuistische Beiträge zur Kenntniss der melanotischen Neubildungen des Auges. Inaug.-Diss. Giessen 1883. 